\title{
Impact of Measurement Error on Synchrophasor Applications
}

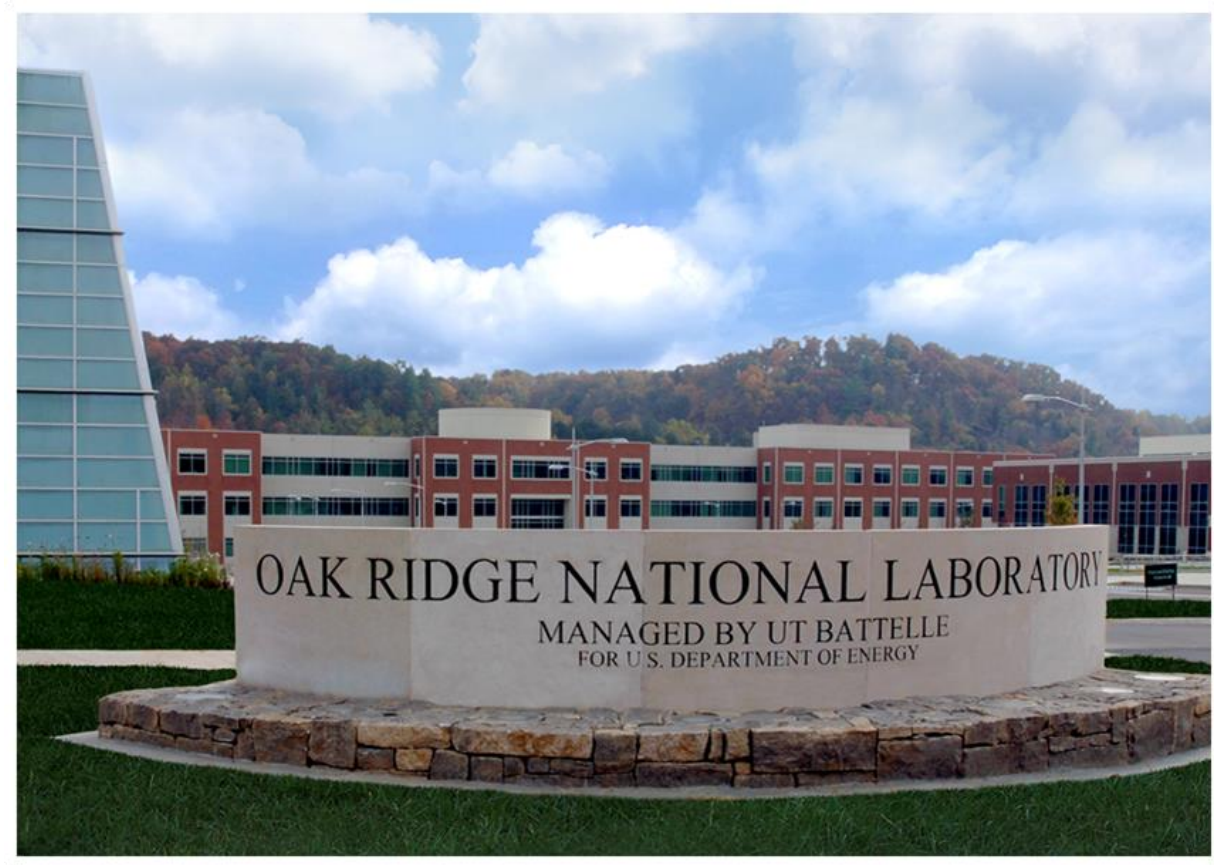

Approved for public release: distribution is unlimited.
Jiecheng Zhao

Jin Tan

Ling Wu

Lingwei Zhan

Yilu Liu Jose R. Gracia

Paul D. Ewing

July 2015 


\section{DOCUMENT AVAILABILITY}

Reports produced after January 1, 1996, are generally available free via US Department of Energy (DOE) SciTech Connect.

Website http://www.osti.gov/scitech/

Reports produced before January 1, 1996, may be purchased by members of the public from the following source:

National Technical Information Service

5285 Port Royal Road

Springfield, VA 22161

Telephone 703-605-6000 (1-800-553-6847)

TDD 703-487-4639

Fax 703-605-6900

E-mail info@ntis.gov

Website http://www.ntis.gov/help/ordermethods.aspx

Reports are available to DOE employees, DOE contractors, Energy Technology Data Exchange representatives, and International Nuclear Information System representatives from the following source:

Office of Scientific and Technical Information

PO Box 62

Oak Ridge, TN 37831

Telephone 865-576-8401

Fax 865-576-5728

E-mail reports@osti.gov

Website http://www.osti.gov/contact.html

This report was prepared as an account of work sponsored by an agency of the United States Government. Neither the United States Government nor any agency thereof, nor any of their employees, makes any warranty, express or implied, or assumes any legal liability or responsibility for the accuracy, completeness, or usefulness of any information, apparatus, product, or process disclosed, or represents that its use would not infringe privately owned rights. Reference herein to any specific commercial product, process, or service by trade name, trademark, manufacturer, or otherwise, does not necessarily constitute or imply its endorsement, recommendation, or favoring by the United States Government or any agency thereof. The views and opinions of authors expressed herein do not necessarily state or reflect those of the United States Government or any agency thereof. 


\title{
IMPACT OF MEASUREMENT ERROR ON SYNCHROPHASOR APPLICATIONS
}

\author{
Jiecheng Zhao* \\ Jin Tan* \\ Ling $\mathrm{Wu}^{*}$ \\ Lingwei Zhan* \\ Yilu Liu ${ }^{\dagger *}$ \\ Jose R. Gracia ${ }^{\dagger}$ \\ Paul D. Ewing ${ }^{\dagger}$ \\ *University of Tennessee, Knoxville \\ ${ }^{\dagger}$ Oak Ridge National Laboratory
}

Date Published: July 2015

Prepared by

OAK RIDGE NATIONAL LABORATORY

Oak Ridge, TN 37831-6283

managed by

UT-BATTELLE, LLC

for the

US DEPARTMENT OF ENERGY

under contract DE-AC05-00OR22725 



\section{CONTENTS}

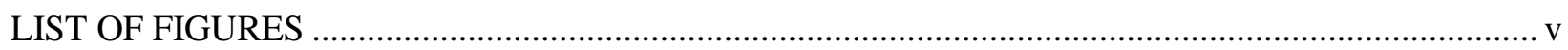

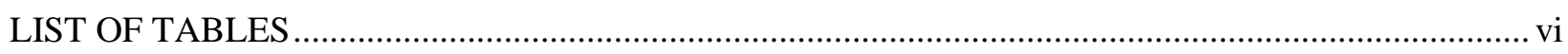

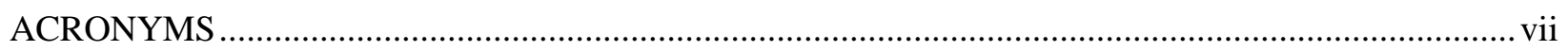

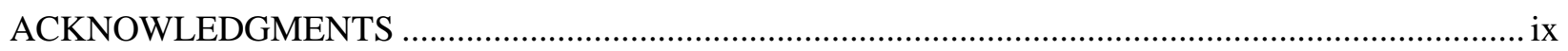

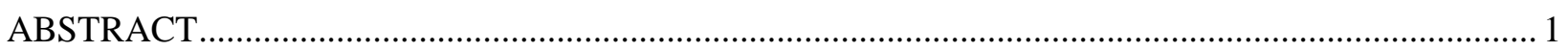

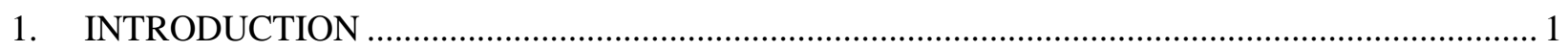

1.1 PHASOR MEASUREMENT UNIT APPLICATIONS....................................................... 1

1.2 PHASOR MEASUREMENT UNIT ERRORS …............................................................... 2

1.3 INSTRUMENTATION CHANNEL ERRORS ................................................................ 2

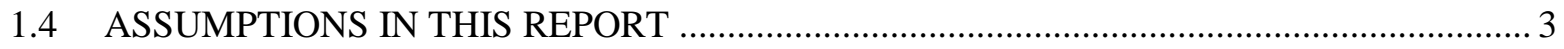

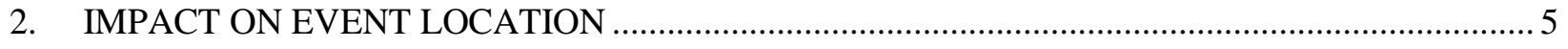

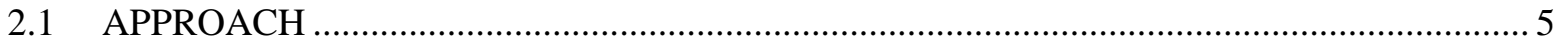

2.2 NORTHEAST POWER COORDINATING COUNCIL MODEL-BASED

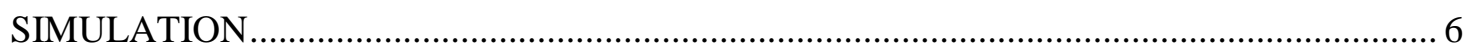

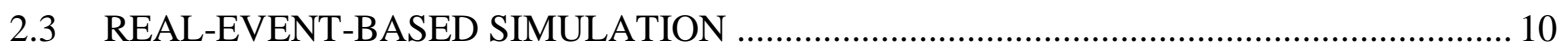

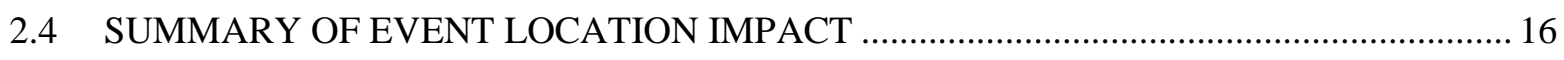

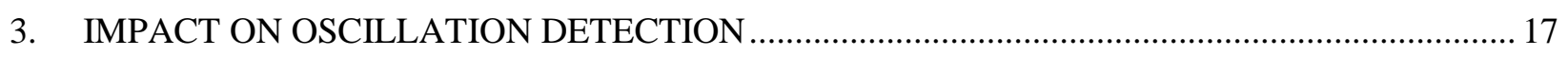

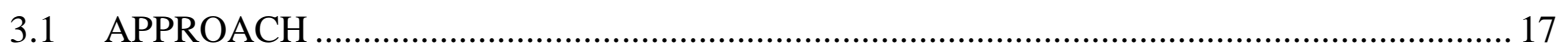

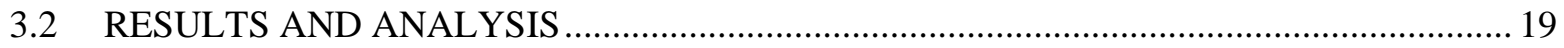

3.3 SUMMARY OF OSCILLATION DETECTION IMPACT …............................................ 21

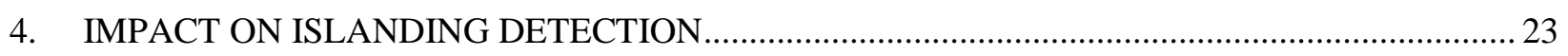

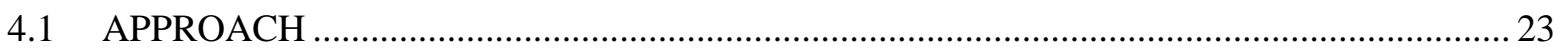

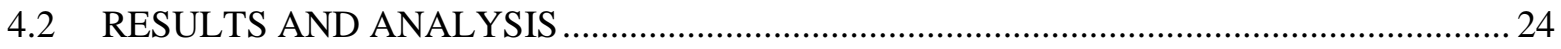

4.3 SUMMARY OF ISLANDING DETECTION IMPACT ...................................................... 28

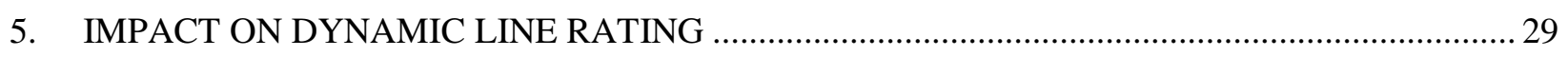

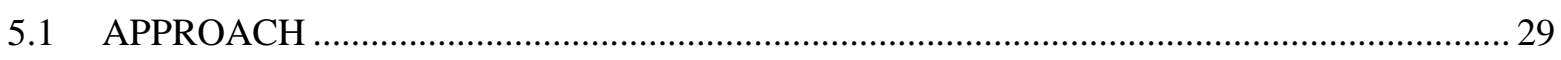

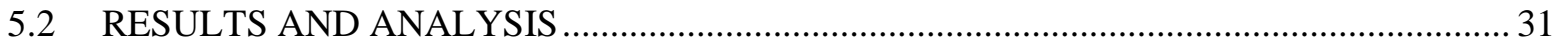

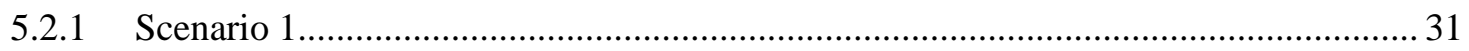

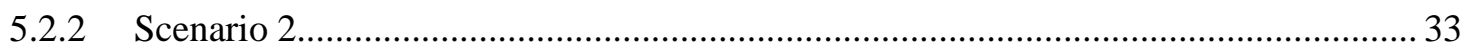

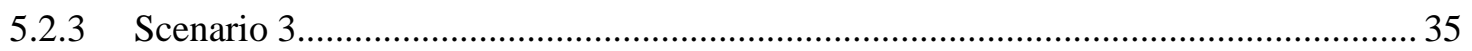

5.3 SUMMARY OF DYNAMIC LINE RATING IMPACT ................................................. 36

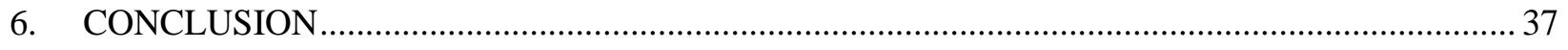

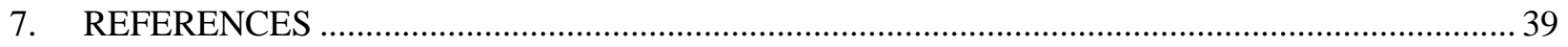

APPENDIX A. APPLICATIONS OF PHASOR MEASUREMENT UNITS ........................................ A-1

APPENDIX B. DYNAMIC LINE RATING MODEL ...................................................................... B-1

APPENDIX C. INPUT DATA FOR DYNAMIC LINE RATING MODEL …..................................... C-1 



\section{LIST OF FIGURES}

1.1. Typical instrumentation channel for a phasor measurement unit............................................... 3

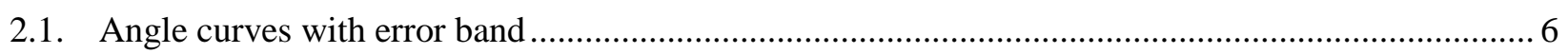

2.2. Northeast Power Coordinating Council model ........................................................................... 7

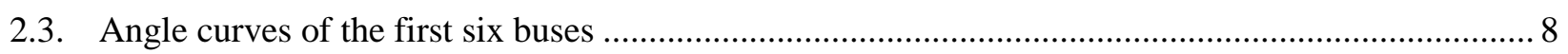

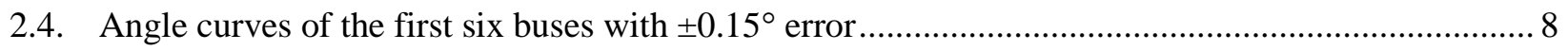

2.5. Angle curves of the first six buses with $\pm 0.6^{\circ}$ error ................................................................... 9

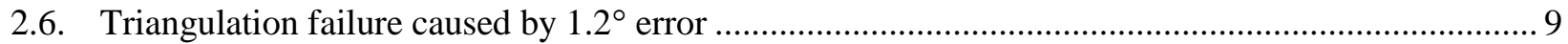

2.7. The processed phase angle curves measured by frequency difference recorders in a

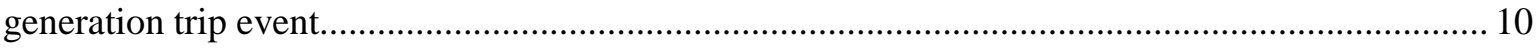

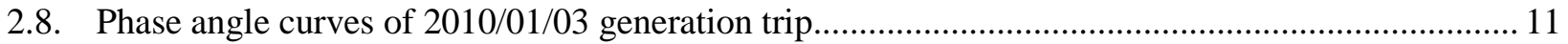

2.9. Phase angle curves of 2010/03/14 generation trip....................................................................... 11

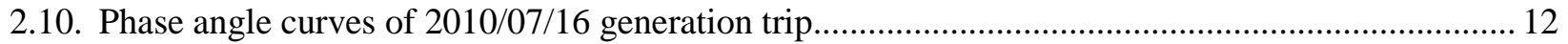

2.11. Phase angle curves of 2011/05/09 generation trip...................................................................... 12

2.12. Phase angle curves of 2011/06/26 generation trip..................................................................... 13

2.13. Phase angle curves of 2011/10/12 generation trip.................................................................... 13

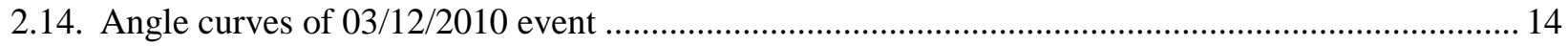

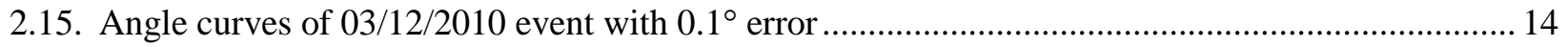

2.16. Angle curves of $03 / 12 / 2010$ event with $\pm 0.6^{\circ}$ error .................................................................. 15

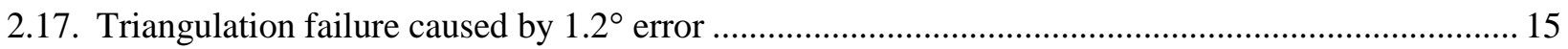

3.1. Angle measurement vs. frequency measurement in oscillation detection....................................... 18

3.2. Schematic of the angle-based oscillation detection.................................................................... 19

3.3. Phasor measurement unit error impact on an oscillation signal .................................................. 19

3.4. Phasor measurement unit error impact on a nonoscillation signal ............................................. 20

3.5. Phasor measurement unit error impact on oscillation signal ....................................................... 21

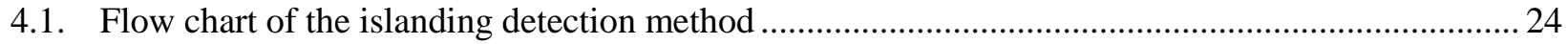

4.2. Frequency measured by frequency disturbance recorders in the

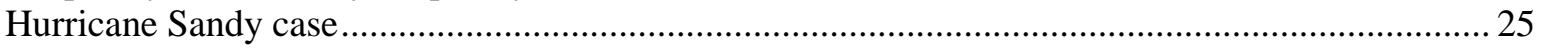

4.3. Frequency with $0.35 \mathrm{~Hz}$ error in the Hurricane Sandy case ......................................................25

4.4. Frequencies measured by frequency disturbance recorders in the 2010/06/01 Western Electricity Coordinating Council islanding case .......................................... 26

4.5. Frequencies with $0.2 \mathrm{~Hz}$ error in the $2010 / 06 / 01$ Western Electricity Coordinating Council islanding case .....

4.6. Frequencies measured by frequency disturbance recorders in the 2010/07/22 Western Electricity Coordinating Council islanding case 
4.7. Frequencies with $0.2 \mathrm{~Hz}$ error in the $2010 / 07 / 22$ Western Electricity Coordinating Council islanding case

5.1. Transmission line with phasor measurement units at both ends

5.2. Overall framework of phasor measurement unit (PMU)-based dynamic line rating technology

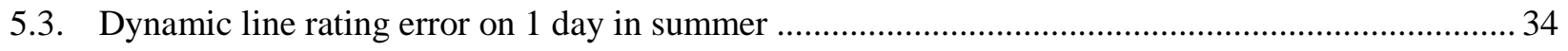

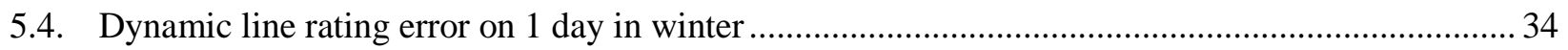

5.5. Impact of wind speed, temperature, and solar heat gain on dynamic line rating error.

\section{LIST OF TABLES}

5.1. Phasor measurement unit error impact on dynamic line rating with different error directions

7.1. Effect of measurement error on applications 


\section{ACRONYMS}

ACSR aluminum conductor, steel-reinforced

ADC analog-to-digital converter

CT

current transformer

CCVT capacitive coupled voltage transformer

DFT

DG

discrete Fourier transform

DLR

distributed generation

EI

dynamic line rating

FD

Eastern Interconnection

FDR

frequency deviation

FNET

frequency disturbance recorder

GPS

Frequency Monitoring Network

IOFD

Global Positioning System

LSB

integration of frequency deviation

NPCC

least significant bit

PSD

Northeast Power Coordinating Council

PMU

power spectral density

PPS

phasor measurement unit

PSS/E

pulse-per-second

RMS

Siemens Power System Simulator for Engineering

SLR

root mean square

SNR

static line rating

TDOA

signal-to-noise ratio

THD

time difference of arrival

TVE

total harmonic distortion

UTC

total vector error

VT

Coordinated Universal Time

WECC

voltage transformer

Western Electricity Coordinating Council 



\section{ACKNOWLEDGMENTS}

The authors would like to thank Ye Zhang [University of Tennessee-Knoxville (UTK)], Dao Zhou (UTK), Jiahui Guo (UTK), Gefei, Kou (UTK), Dr. Kai Sun (UTK), Denis Osipov (UTK), David Bertagnolli (ISO New England) and Kyle Thomas (Dominion Virginia Power) for discussions and technical assistance in creating this report. The authors would also like to acknowledge the careful and detailed review on language by Samantha White (UTK) and technical editing by Vj Ewing (Oak Ridge National Laboratory). 



\begin{abstract}
Phasor measurement units (PMUs), a type of synchrophasor, are powerful diagnostic tools that can help avert catastrophic failures in the power grid. Because of this, PMU measurement errors are particularly worrisome. This report examines the internal and external factors contributing to PMU phase angle and frequency measurement errors and gives a reasonable explanation for them. It also analyzes the impact of those measurement errors on several synchrophasor applications: event location detection, oscillation detection, islanding detection, and dynamic line rating. The primary finding is that dynamic line rating is more likely to be influenced by measurement error. Other findings include the possibility of reporting nonoscillatory activity as an oscillation as the result of error, failing to detect oscillations submerged by error, and the unlikely impact of error on event location and islanding detection.
\end{abstract}

\title{
1. INTRODUCTION
}

First introduced in the 1980s, synchronized phasor measurement units (PMUs) have now become a mature technology used for many applications essential to power system efficiency and integrity (see Appendix A). Linked in synchronized networks, PMUs are capable of reflecting the status of the whole measured power system and are useful for power system stability monitoring, postmortem analysis, and adaptive protection and control and to improve efficiency and lower costs. The measurement of frequency and phase angle, which is used by most applications, is subject to measurement errors from both internal and external factors, which may influence the accuracy of the applications or even cause their failure. This report analyzes the range of PMU measurement errors and then discusses their influence on several applications.

Measurement errors typically originate in the PMU and instrumentation channels between the power line and the PMU. In this section, errors from these two sources are discussed and assumptions for the error impacts are given.

\subsection{PHASOR MEASUREMENT UNIT APPLICATIONS}

PMUs, a kind of synchrophasor, were developed to monitor and analyze power system behavior. The device provides a way to monitor a wide-area power system with very high precision in both distance and time, through the use of its high resolution and time synchronization. Compared to many traditional power system devices, PMUs provide precise frequency and phase angle measurement results. This feature is the basis of many applications for power system monitoring and protection.

Event location estimation is one PMU application. When events such as generation trip or load shedding occur, a sudden mismatch of active power will happen and cause a significant frequency and phase angle increase or decrease depending on the event type. Because these perturbations travel through the grid as electromechanical waves dispersing at finite speeds, PMUs located throughout the grid are able to detect the variation of frequency and angle with unique time delays proportional to the distance from the PMU to the disturbance. Applications based on this have been developed to estimate the event location [1].

Oscillation detection is another PMU application. Disturbances ranging from a small amount of load variation to the loss of a large generator typically evoke voltage, angle, and frequency oscillations in the power system. A system that lacks sufficient ability to damp oscillations can become unstable and even experience cascading blackouts. It wasn't until the advent of PMUs that oscillations could be easily observed [2]. Similar to generation trip events, frequency oscillations propagate through the system as electromechanical waves and therefore can be observed by PMUs. 
As distributed generation (DG) has been more broadly used, it has brought new kinds of problems, one of the most important of which is islanding. Islanding is the situation where a distributed energy resource continues to supply loads when the DG system is disconnected from the utility power system. An islanding occurrence not only poses a threat to power quality and the safety of maintenance crews, but may also seriously damage the DG network and delay restoration [3-5]. When islanding occurs, the islanded part cannot synchronize with the bulk power system, and therefore, a frequency difference between the two parts occurs. By detecting this difference, PMUs can discover the islanding event.

Dynamic line rating (DLR) is used to evaluate the maximum allowable currents of the transmission line in real time. It is essential to maximizing use of the transmission line while avoiding equipment degradation or failure [6]. Using PMUs for DLR can save the cost of installing additional devices while providing real-time, accurate results [7].

\subsection{PHASOR MEASUREMENT UNIT ERRORS}

The standard for PMU accuracy is IEEE Standard for Synchrophasor Measurements for Power Systems (IEEE Std C37.118.1-2011) [8]. According to IEEE Std. C37.118.1-2011, to evaluate the measurement error of PMUs on amplitude and phase difference, total vector error (TVE), defined in Eq. (1.1), is used.

$$
\operatorname{TVE}(n)=\sqrt{\frac{\left(\hat{X}_{r}(n)-X_{r}(n)\right)^{2}+\left(\hat{X}_{i}(n)-X_{i}(n)\right)^{2}}{\left(X_{r}(n)\right)^{2}+\left(X_{i}(n)\right)^{2}}},
$$

where $\hat{X}_{r}(n)$ and $\hat{X}_{i}(n)$ are the sequences of estimates given by the PMU under testing and $X_{r}(n)$ and $X_{i}(n)$ are the sequences of theoretical values of the input signal at the instant of time $(n)$ assigned by the unit to those values.

According to this definition, a phasor angle error of $0.57^{\circ}(0.01$ radian $)$ will cause $1 \%$ TVE, corresponding to a time error of $\pm 26 \mu$ s for a $60 \mathrm{~Hz}$ system. Meanwhile, the standard requires that the maximum steady-state frequency error be less than $0.005 \mathrm{~Hz}$.

\subsection{INSTRUMENTATION CHANNEL ERRORS}

The instrumentation channel refers to the transmission path between the PMU and the measured power

line. The instrumentation channel scales down the amplitude of voltage and current on the power line and passes them to the PMU. Components on the channel usually include transformers, cables, and attenuators, as shown in Fig. 1.1 [9]. 


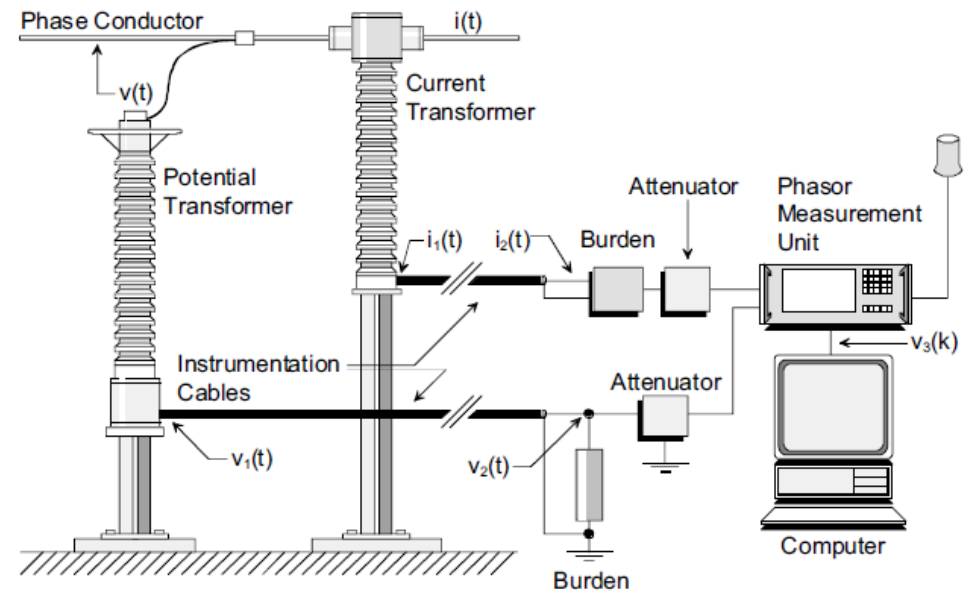

Fig. 1.1. Typical instrumentation channel for a phasor measurement unit

The cable is the main contributor to instrumentation channel errors as its length causes the time delay that is then transmitted to the phase angle error. This delay is also dependent on several other characteristics of the cable, such as the cable type and whether it is shielded or unshielded. Typically a $500 \mathrm{ft}$ RG- 8 cable introduces an error of $0.4^{\circ}$. In some cases, the continuous cable can be as long as 3,000 ft, which brings larger phase angle error [10].

For the sake of economy, the accuracy of the instrumentation channel components is limited, especially that of the transformers [10]. Generally, the most accurate instrumentation channels are current instrumentation channels that use current transformers (CTs), followed by those that use voltage transformers (VTs) and capacitive coupled voltage transformers (CCVTs). For American National Standards Institute-class VTs and CTs, the maximum phase angle error could vary from $0.26^{\circ}$ to $2.08^{\circ}$, depending on the transformer type [10].

\subsection{ASSUMPTIONS IN THIS REPORT}

To evaluate the impact of errors on PMU-based applications, the worst case, defined as the errors in measurement that result in the application deviating to the greatest extent, was assumed for the analysis. For instance, the worst case PMU-based event location error locates an event in the farthest place from the actual event position. All errors are "assigned" to cause this worst case.

The error range is selected in reference to the typical condition. For the PMU error, a phase angle of $0.6^{\circ}$ and a frequency of $0.005 \mathrm{~Hz}$ are assigned. The typical phase angle error brought on by instrumentation channels using VTs or CTs varies from $0.2^{\circ}$ to $1.0^{\circ}$ [10]; therefore, $0.6^{\circ}$ and $1.0^{\circ}$ are chosen as the typical and maximum error, respectively. Maximum errors of $1.6^{\circ}$ in phase angle measurement and $0.005 \mathrm{~Hz}$ in frequency are assumed. As long as the errors are within these ranges, it is possible for the selected scenario to occur. 



\section{IMPACT ON EVENT LOCATION}

One application of PMUs is detecting and locating disturbance events within a power grid. The method for this is based on the geometrical triangulation algorithm using the time difference of arrival (TDOA). A disturbance in the power system, such as generator trip or load shedding, causes frequency and phase angle variations that propagate along the power network with finite and constant speeds [11]. Using this principle, it is possible to estimate the location of the disturbance [12]. This application is used by the power system Frequency Monitoring Network (FNET) [13]. When a disturbance occurs, changes over a preset threshold will be detected by frequency disturbance recorders (FDRs) on the distribution lines and transmitted to the FNET server. The server will detect the event and determine its arrival time at different FDRs. The triangulation algorithm is then used to estimate the location within a circle around the first responding FDR as it is the nearest one to the event location. Every suspected power plant and pumped hydroelectric storage unit within this circle is then validated by a linear regression with the data from the first six responding FDRs. The event plant should give the least fitting residues [1]. Because the algorithm is based on the phase angle measured from the power grid, measurement error may cause the event location to be inaccurate or fail altogether. This section presents a study designed to analyze the level of angle error that will cause event location failure.

\subsection{APPROACH}

Because the event location is estimated within a circle around the first responding PMU/FDR, the location triangulation will definitely fail if the first responding device is impacted by error and the real location is beyond the circle. As the triangulation algorithm uses relative angle values to detect the first responding unit, we assumed that the impact of instrumentation channel error would be negligible in this case. That is because all measurement data go through the same channel and contain consistent angle shifts that can be eliminated during the process of relative angle value calculation. We assumed that, for every single PMU, the portion of measurement error that impacts the event location application is randomly distributed in the whole process of measurement within a reasonable band. Based on IEEE Std. C37.118.1-2011 [8], $\pm 0.6^{\circ}$ was taken as the maximum PMU measurement error band. Plots of the angle curves are presented throughout this discussion. The units are seconds for the time and degrees for the angles.

According to the triangulation algorithm, the closer the angle curves are to each other, the more easily they tend to be influenced by error. An example is shown in Fig. 2.1. The red horizon line represents the preset threshold. The response time of each PMU is decided by the time its angle curve goes through this threshold. The angle curves of BUS1 and BUS4 vary within their respective band ranges when error is added. If the error is large enough or the angle plots are close enough, the bands will overlap, and their responding sequences may swap, depending on the measurement error. In that case, the first responding PMU will change from BUS1 to BUS4, resulting in a triangulation failure. 


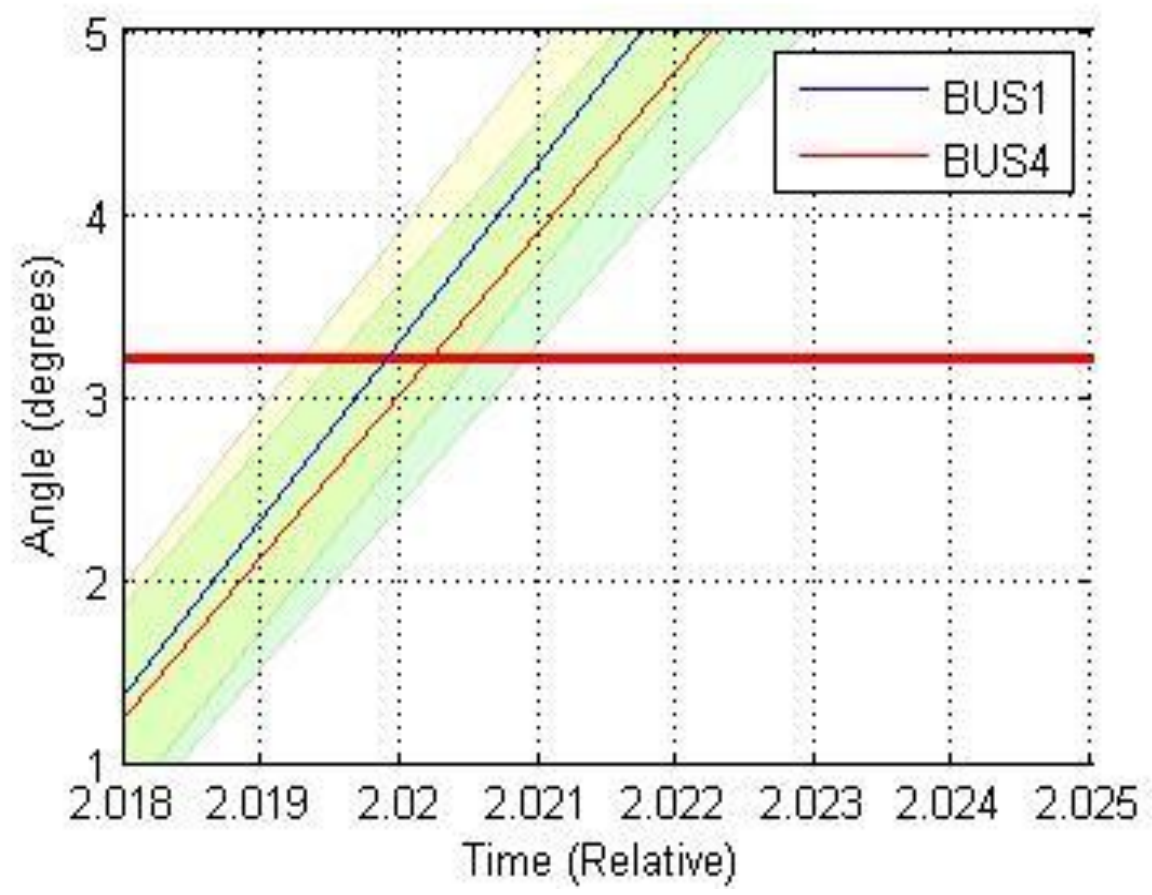

Fig. 2.1. Angle curves with error band.

Within the error band, the theoretical PMU measurement error should randomly distribute. To statistically determine the situations in which the triangulation results would definitely fail would cost much time and most of the answers might be negative. Assuming the worst case occurs when each PMU measurement contains the maximum error, either $+0.6^{\circ}$ or $-0.6^{\circ}$, there are hundreds of "first six responding unit" sequences for one event, which may or may not result in different event location results. It depends on the geographical and electrical relationships between the true event location and the topology of the PMUs. For the sake of efficiency, different events were tested with several combinations of responding PMU sequences to verify the existence of PMU measurement error impacts. This report focuses on the cases that verify the PMU measurement error significantly impacts the event location results.

To demonstrate how the angle error of the PMU impacts event location, angle error is added to different cases, and the triangulation results before and after the error are added and compared. The study is first implemented on a Northeast Power Coordinating Council (NPCC) model-based simulation and then on real power disturbance events. In the first simulation, one generator in the NPCC model is manually tripped and data from each bus are obtained using the Siemens Power System Simulator for Engineering (PSS/E). The latter case uses a real event and the related phase angles recorded by FNET.

The main parameters of the algorithm include the event detection threshold, which indicates how much phase angle change is considered an event, and the search radius, which defines the scale of the circle centering the first responding device and supposing to compromise the event location. Both parameters use empirical values. According to [1], 3.2 ${ }^{\circ}$ is used as the threshold of phase angle variation and 200 miles as the circle radius.

\subsection{NORTHEAST POWER COORDINATING COUNCIL MODEL-BASED SIMULATION}

The NPCC model is shown in Fig. 2.2. There are a total of 140 buses; the phase angle of each is recorded by a virtual PMU in PSS/E. 


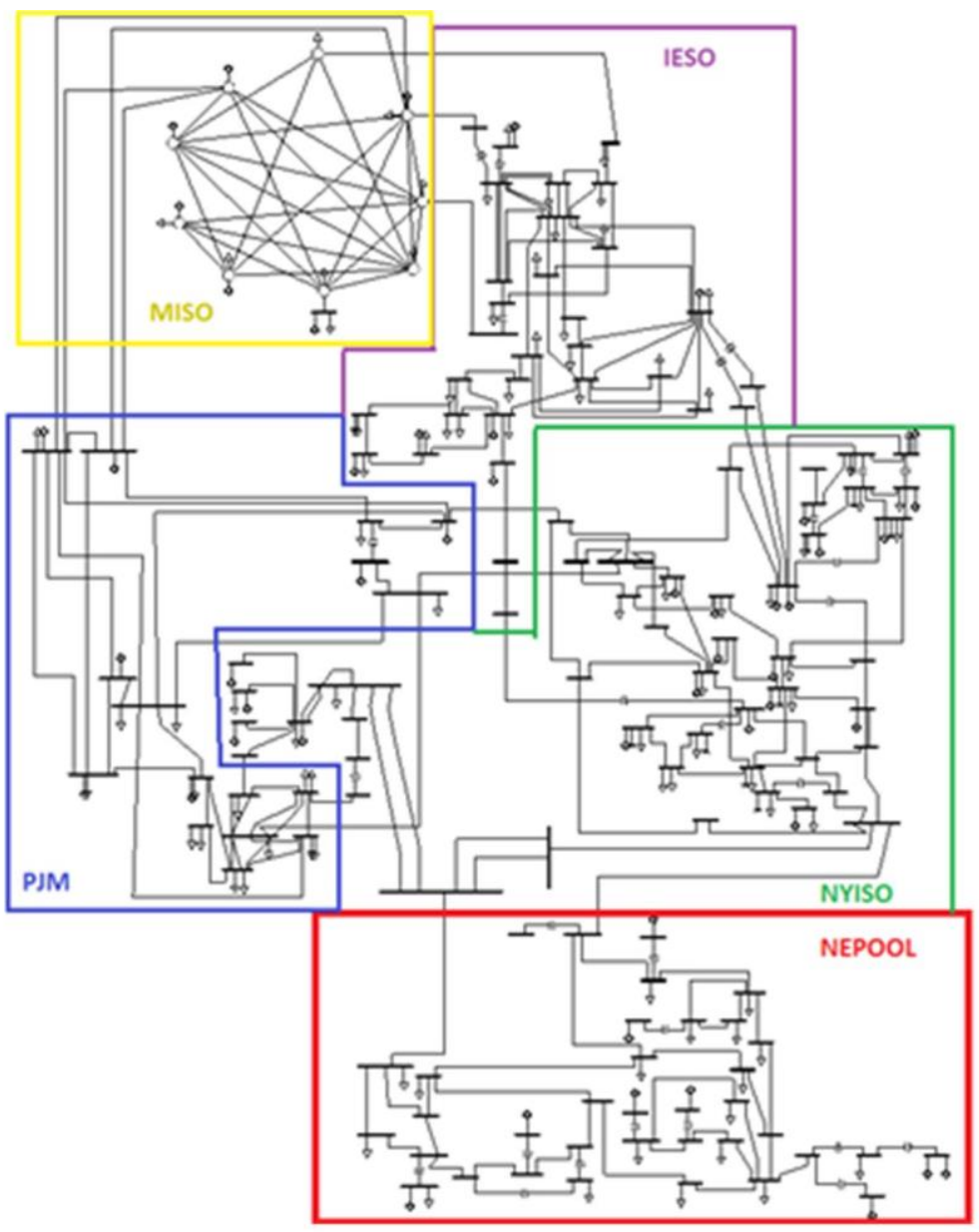

MISO: Midwest Independent System Operator IESO: Independent Electricity System Operator PJM: Pennsylvania, Jersey, Maryland Power Pool NYISO: New York Independent System Operator NEPOOL: New England Power Pool

Fig. 2.2. Northeast Power Coordinating Council model. (Acronyms used in the figure, such as "PJM" and "NYISO," are the names of or stand for regional transmission organizations.)

In the simulation, generator 1 on Bus 21 is tripped down. All PMUs on other buses respond to this event; angles of the first six units are plotted in Fig. 2.3. It is noted from the figure that the first responding PMU is on Bus 1, which is actually the nearest one to Bus 21 . 


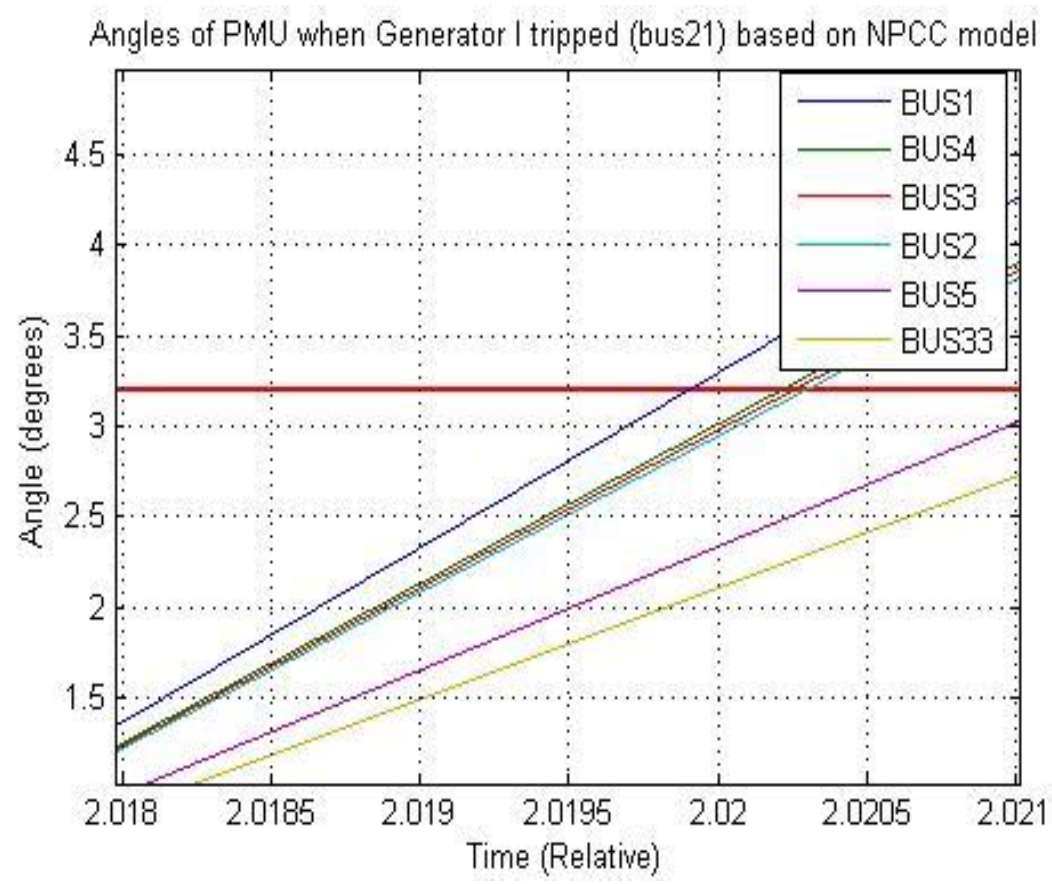

Fig. 2.3. Angle curves of the first six buses. The red horizon line represents the preset threshold.

When angle errors are added, the first responding PMU will change. During the simulation, angle errors with different polarities are added to each bus. It is found that an angle error as small as $\pm 0.15^{\circ}$ is able to change the first responding PMU. In this scenario, $-0.15^{\circ}$ and $+0.15^{\circ}$ error are mixed to Bus 1 and Bus 4 , respectively. Consequently, the first responding FDR changes from Bus 1 to Bus 4, as shown in Fig. 2.4.

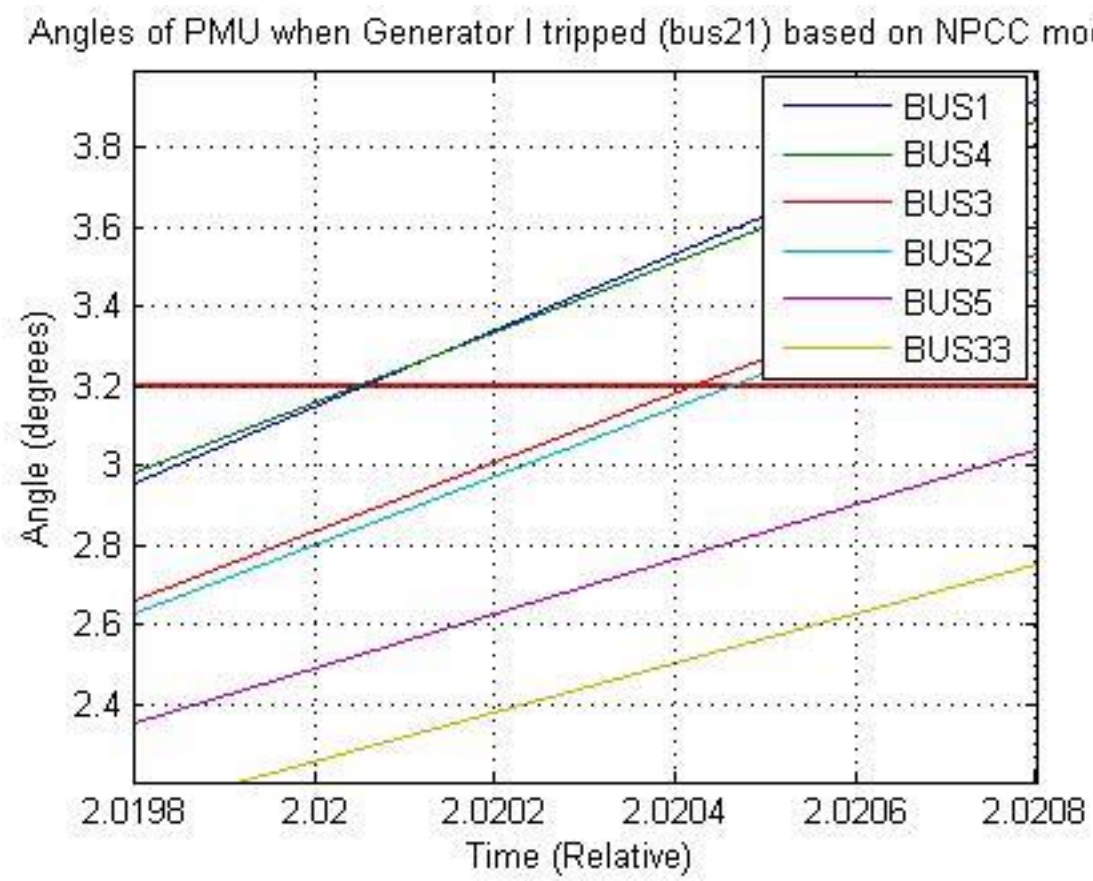

Fig. 2.4. Angle curves of the first six buses with $\pm 0.15^{\circ}$ error. The red horizon line represents the preset threshold. 
When the angle error increased to $\pm 0.6^{\circ}$, the responding time of Bus 1 is far behind Bus 3 and Bus 2, as shown in Fig. 2.5. In this case, the location triangulation will experience a larger impact.

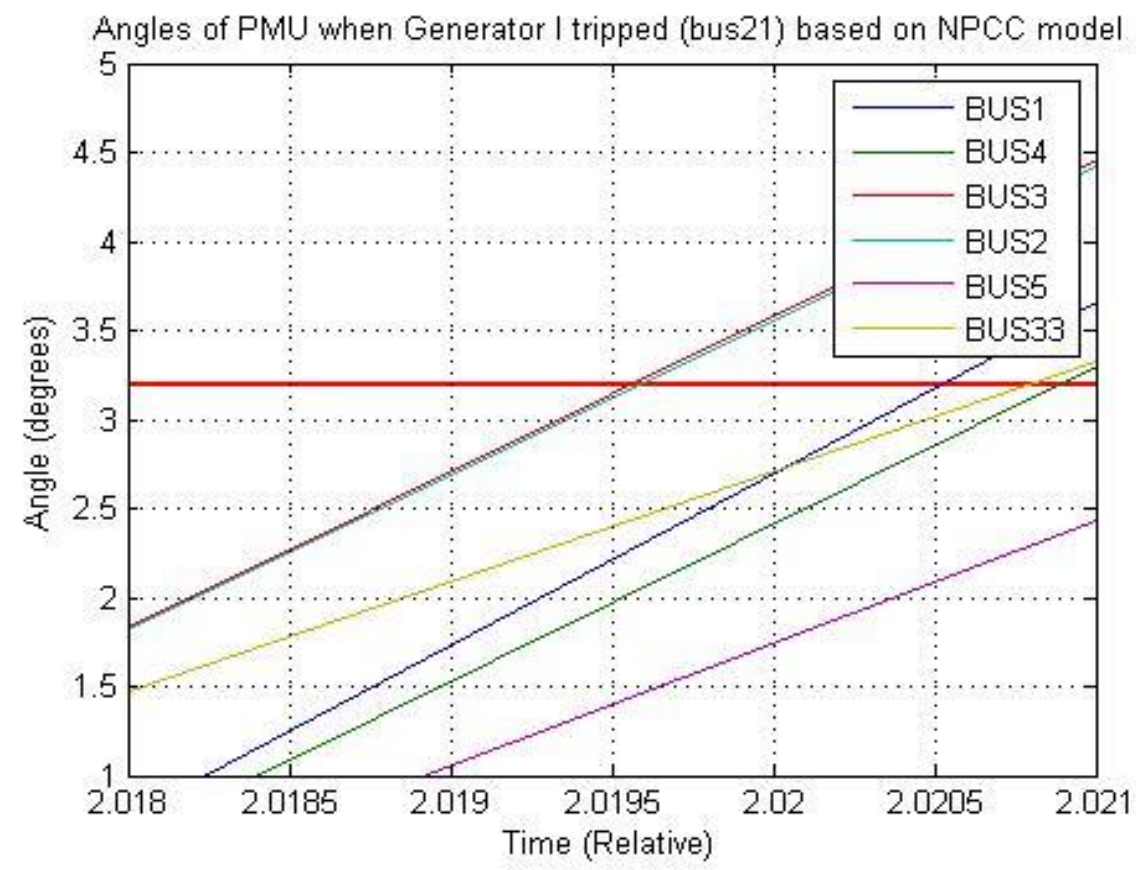

Fig. 2.5. Angle curves of the first six buses with $\pm 0.6^{\circ}$ error. The red horizon line represents the preset threshold.

If the triangulation algorithm implements a radius of 8 miles, the event location is out of the circle around Bus 4, as shown in Fig. 2.6.

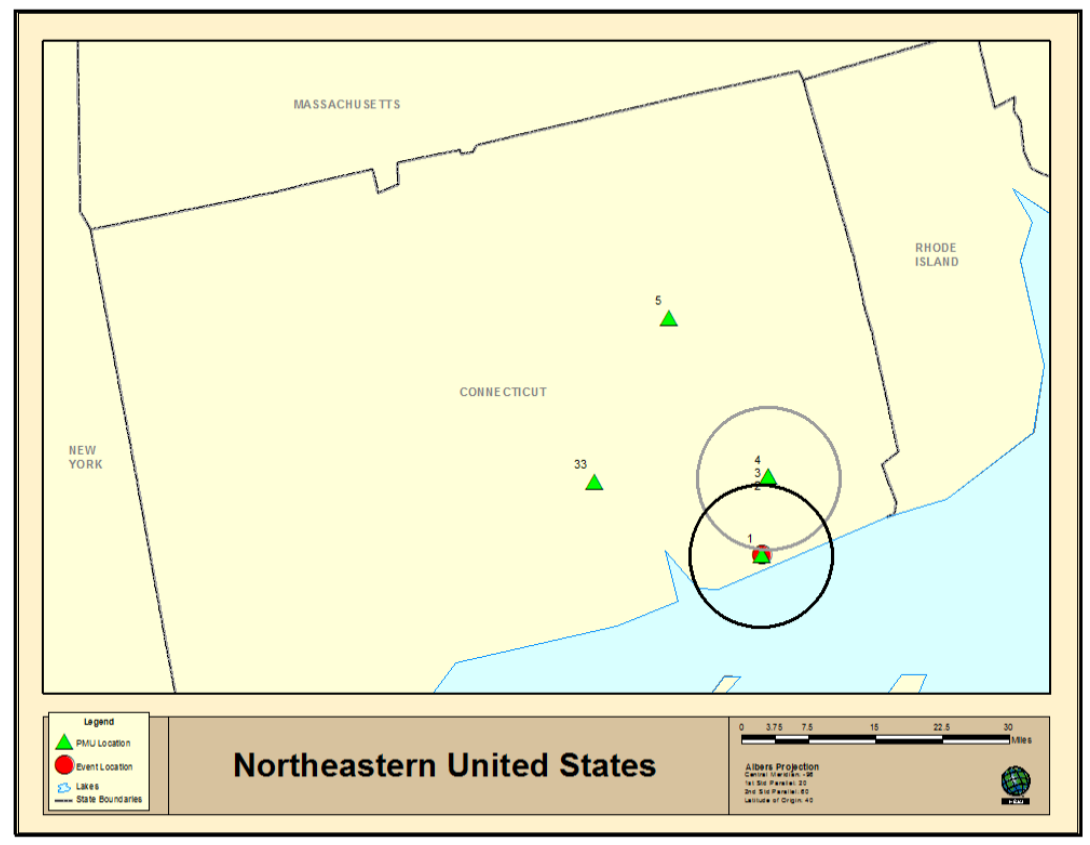

Fig. 2.6. Triangulation failure caused by $1.2^{\circ}$ error. The red circle represents the event location, and the green triangles represent the PMUs. 


\subsection{REAL-EVENT-BASED SIMULATION}

The phase angle variations during a real event are recorded by FDRs deployed around the states and are used for event location. Due to the different initial phase angle in different FDR locations and the angle shifts from high-voltage transmission networks to distribution levels, the phase angles measured by FDRs are far apart from each other. For convenience all the phase angles are self-normalized to start from zero and "detrended" to remove the monotonic increasing or decreasing trend before the disturbance point. After processing, the angles of different locations are comparable and it is easy to ensure the TDOA. An example is shown in Fig. 2.7.
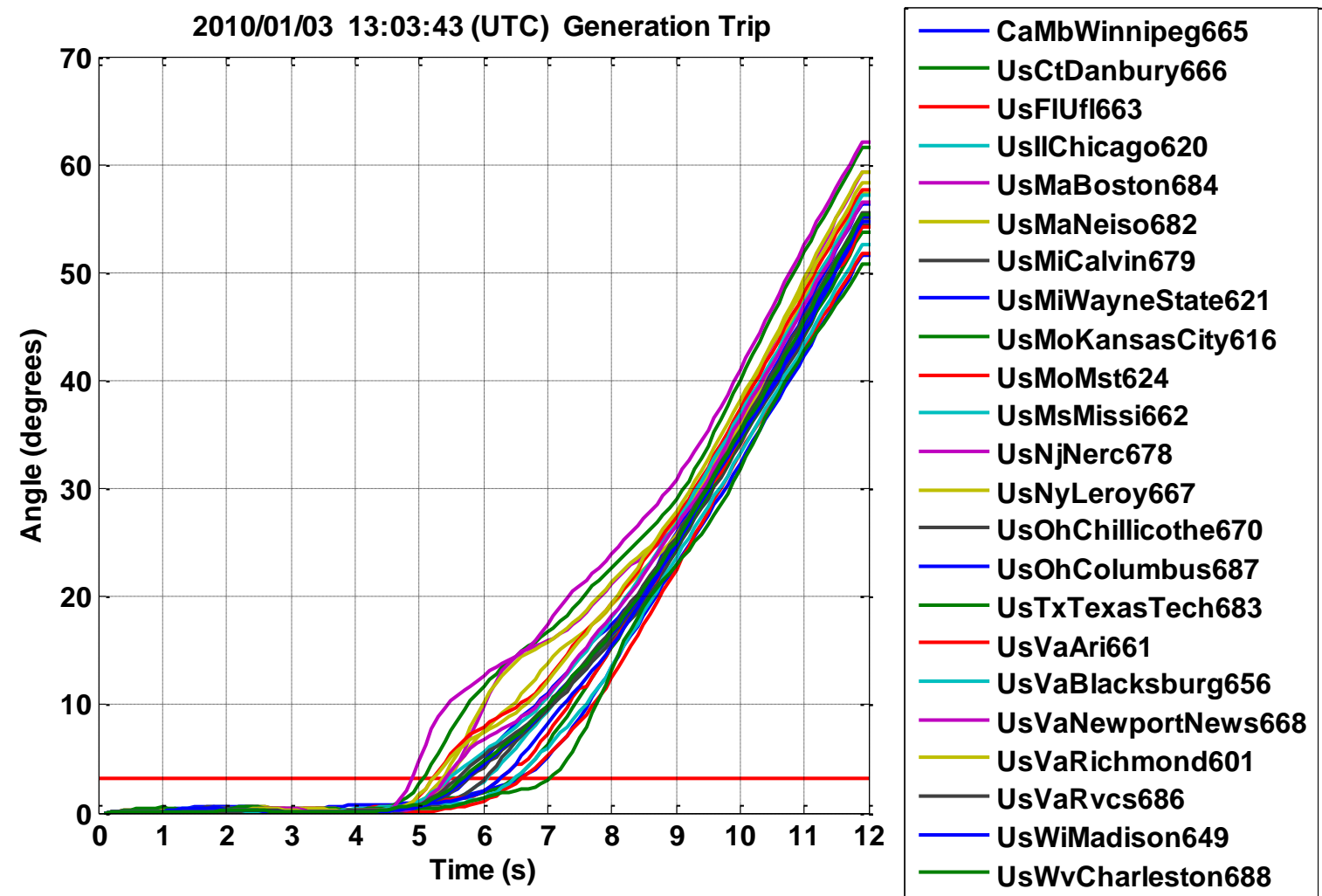

Fig. 2.7. The processed phase angle curves measured by frequency difference recorders in a generation trip event. Coordinated Universal Time (UTC) is used to indicate the time the event occurred. The red horizon line represents the preset threshold. Legends show the names of different frequency disturbance recorders.

In most cases, phase angle curves are separated from each other by a relatively large distance. Therefore, the first responding unit is unlikely to change even with a $\pm 0.6^{\circ}$ error added. The phase angle plots of different generation trip events are shown in Fig. 2.8-2.13. Bands have been added around the phase angle plots to show the possible $\pm 0.6^{\circ}$ variation range due to the error. From the figures it is obvious that the first responding units in these cases will remain unchanged even if the error in each case reaches the maximum value. 


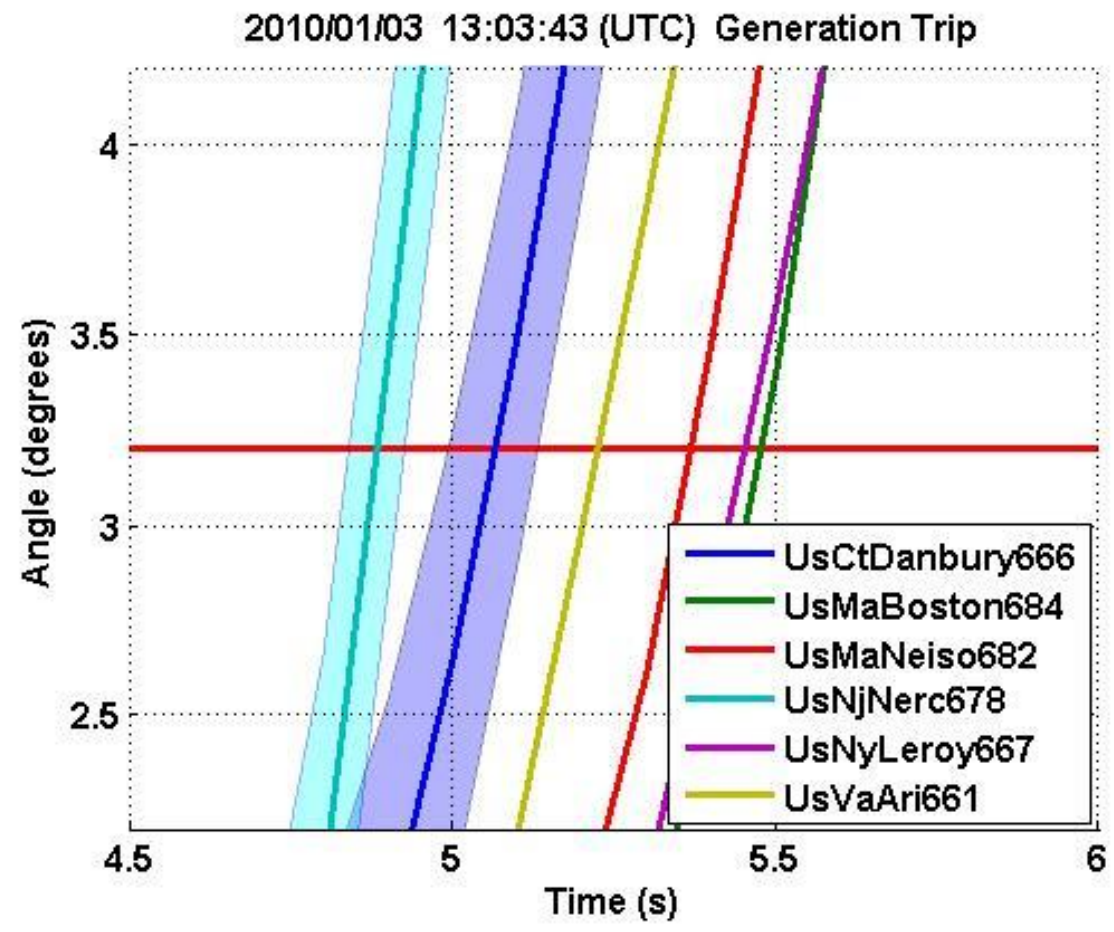

Fig. 2.8. Phase angle curves of 2010/01/03 generation trip. The red horizon line represents the preset threshold.

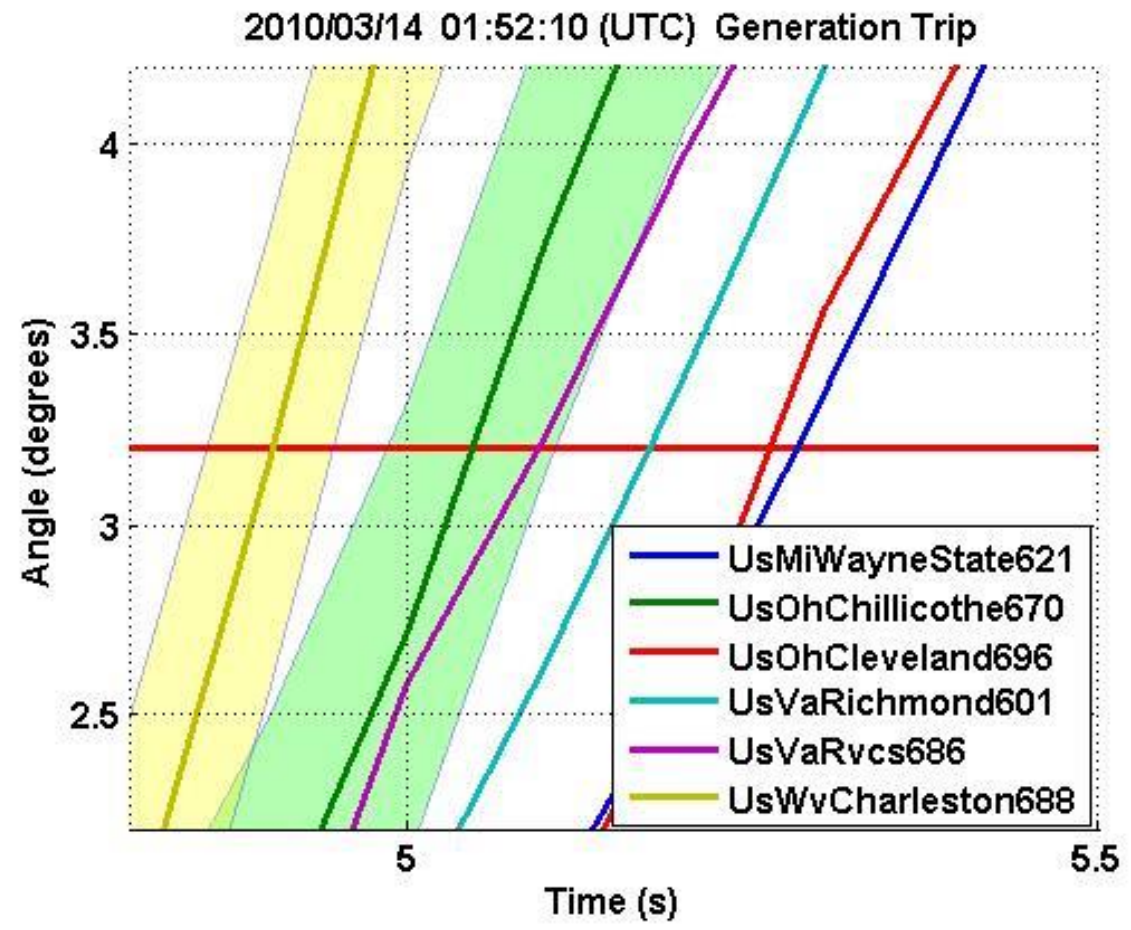

Fig. 2.9. Phase angle curves of $2010 / 03 / 14$ generation trip. The red horizon line represents the preset threshold. 


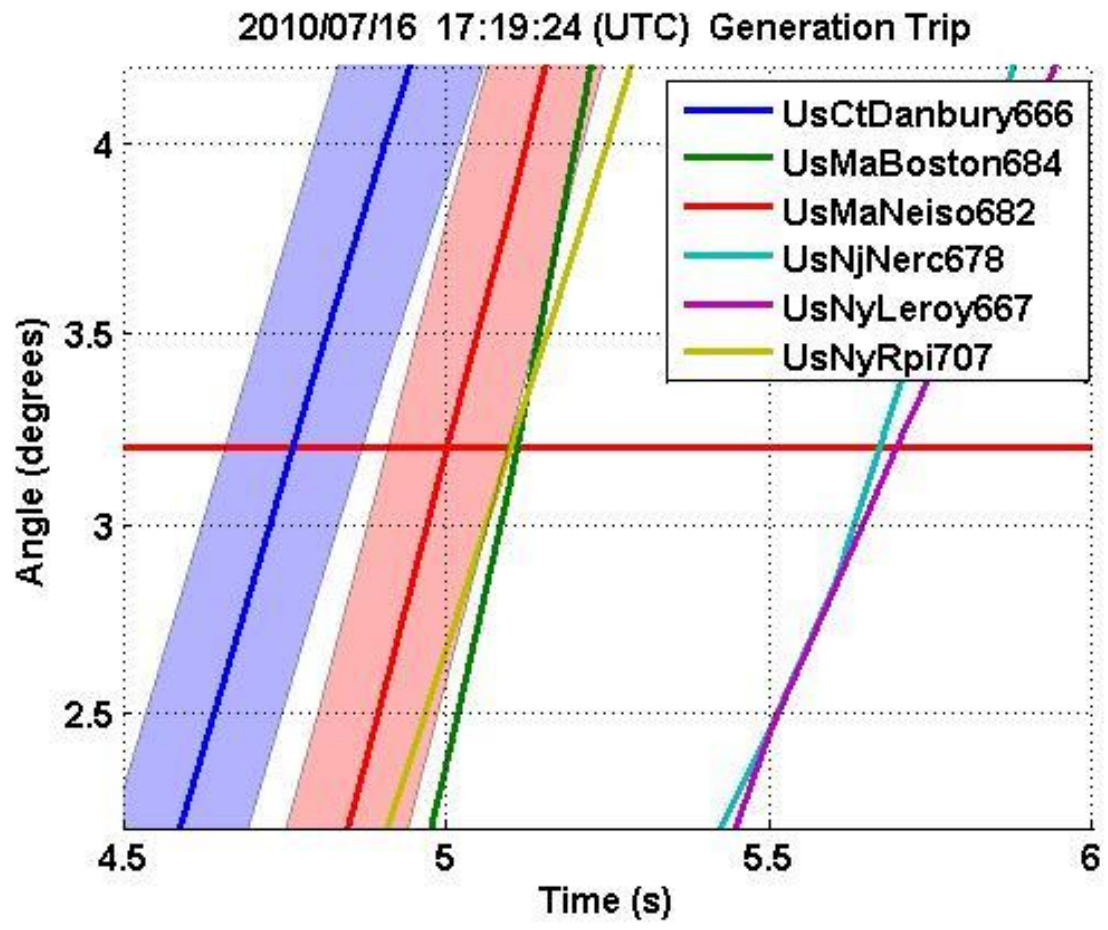

Fig. 2.10. Phase angle curves of 2010/07/16 generation trip. The red horizon line represents the preset threshold.

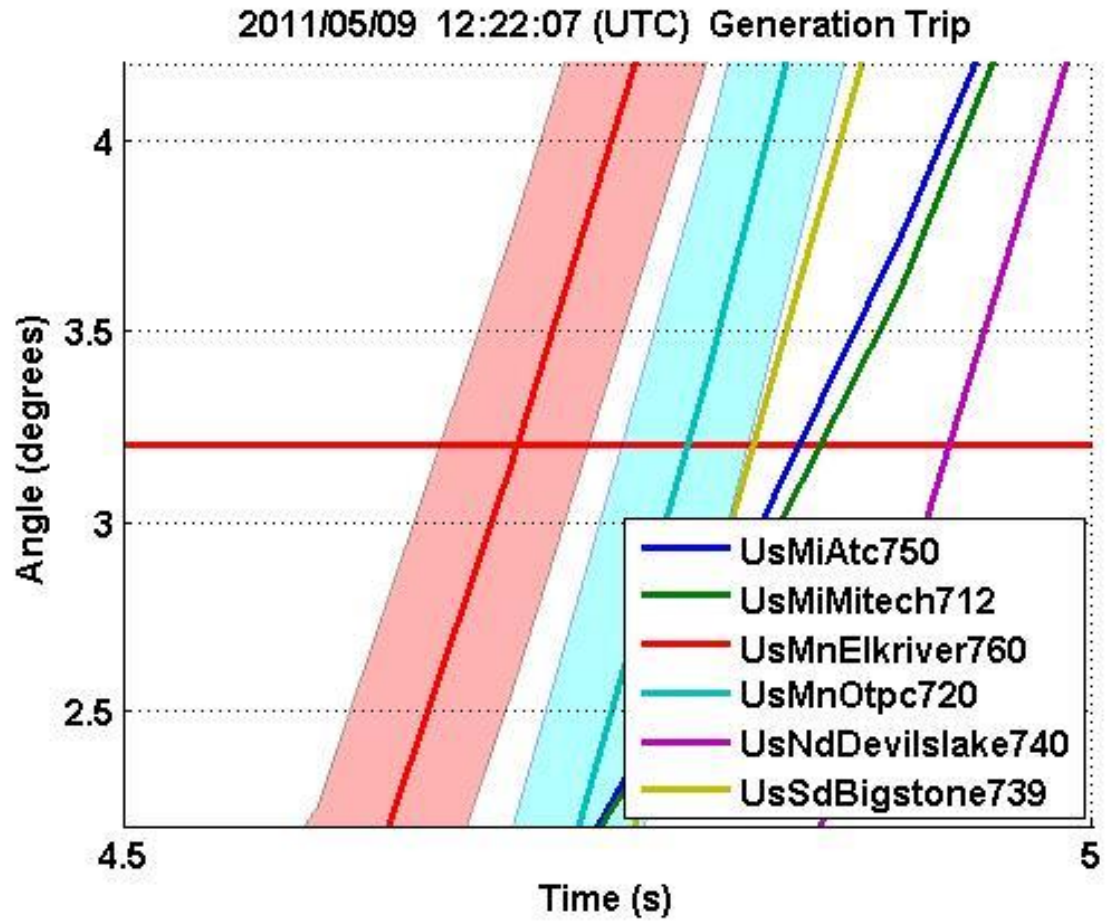

Fig. 2.11. Phase angle curves of 2011/05/09 generation trip. The red horizon line represents the preset threshold. 


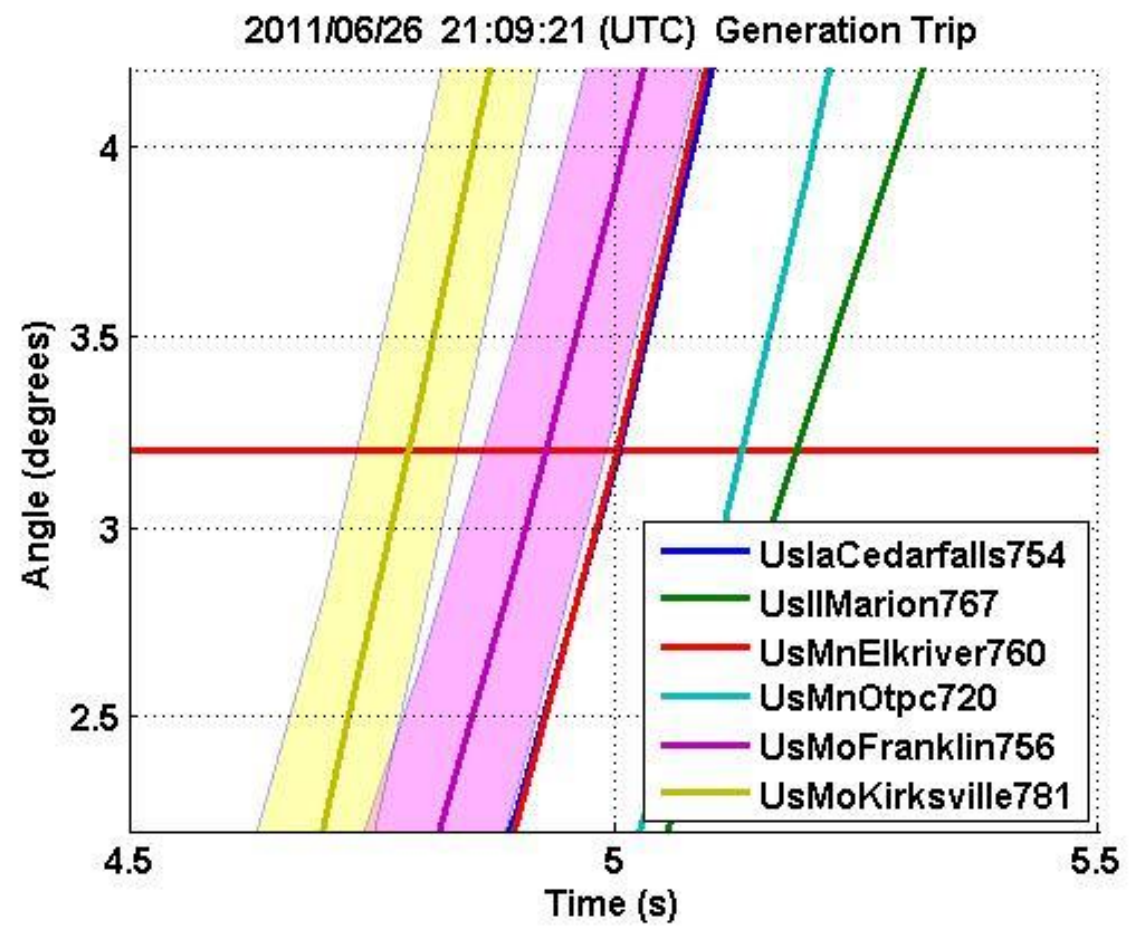

Fig. 2.12. Phase angle curves of 2011/06/26 generation trip. The red horizon line represents the preset threshold.

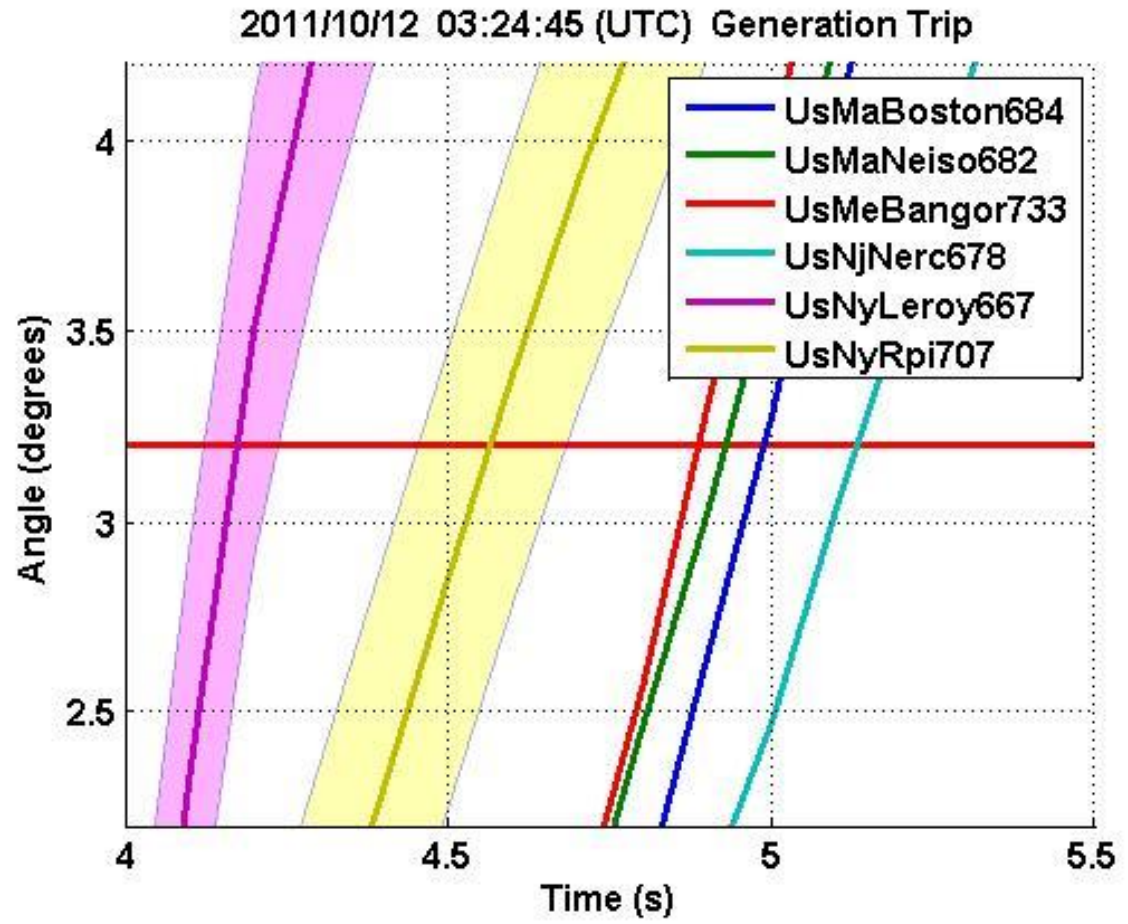

Fig. 2.13. Phase angle curves of 2011/10/12 generation trip. The red horizon line represents the preset threshold. 
According to our simulations, in spite of the $\pm 0.6^{\circ}$ phase angle error being difficult to influence in most cases, the event location still has the potential to be impacted. In this simulation a generation trip event took place in West Virginia on March 12, 2010. The first responding FDR is UsWvCharleston688, which is 26.45 miles from the event location. The curves of the first six responding FDRs are shown in Fig. 2.14.

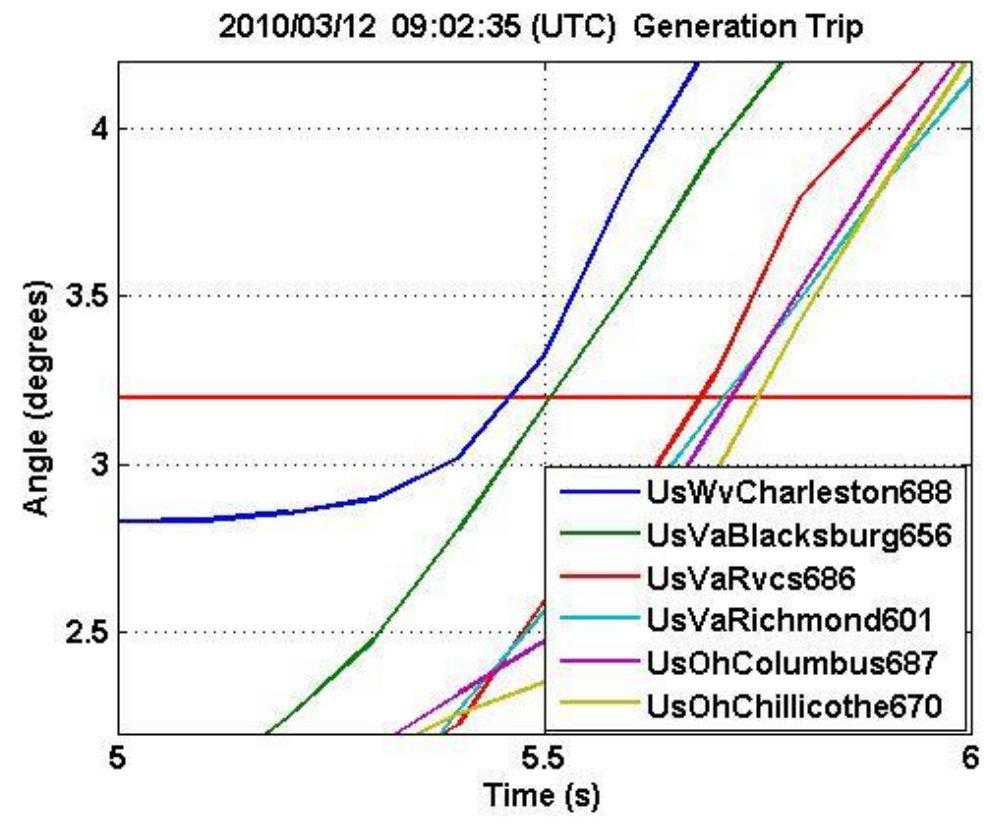

Fig. 2.14. Angle curves of $03 / 12 / 2010$ event. The red horizon line represents the preset threshold.

If the angle error is added, the first responding FDR would change. According to the simulation, an error as low as $0.1^{\circ}$ could change the FDR responding sequence. One example is shown in Fig. 2.15.

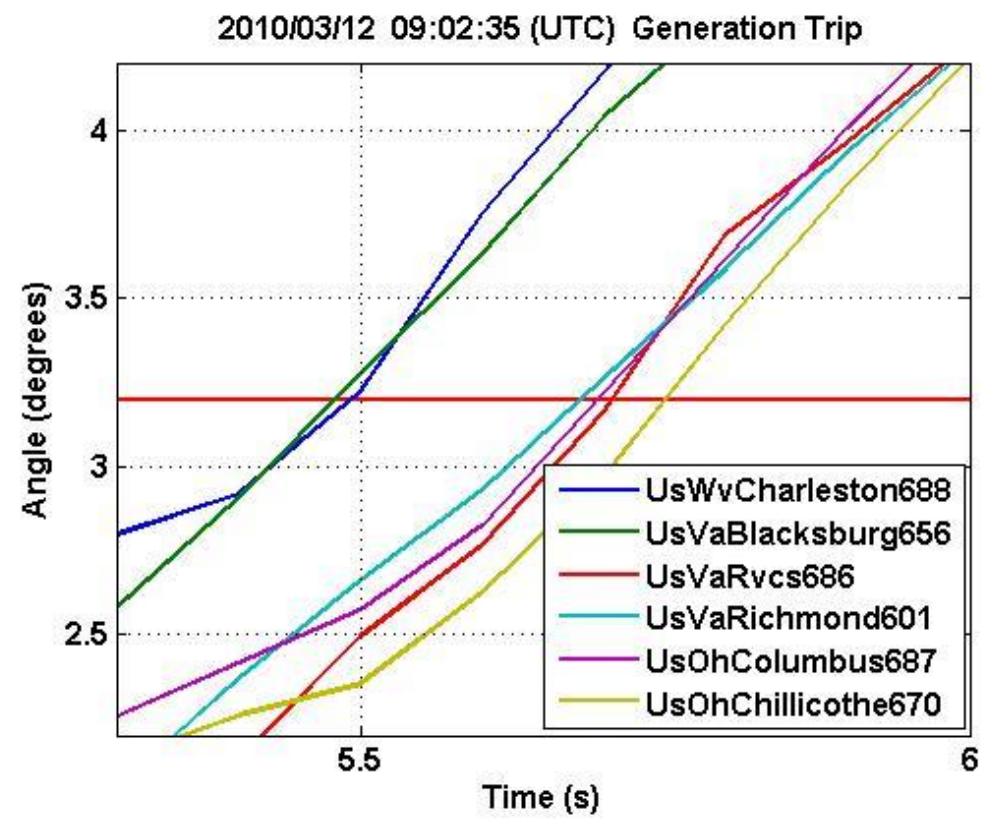

Fig. 2.15. Angle curves of $03 / 12 / 2010$ event with $0.1^{\circ}$ error.

The red horizon line represents the preset threshold. 
In Fig. 2.15, the first responding FDR varied from UsWvCharleston688 to UsVaBlacksburg656, and the responding sequence of others and TDOA also changed due to the $\pm 0.1^{\circ}$ error that is added.

When the error increased to $\pm 0.6^{\circ}$, the first responding FDR could be changed to UsVaRichmond601, which is 255 miles from the event location. Angle curves of this scenario are shown in Fig. 2.16.

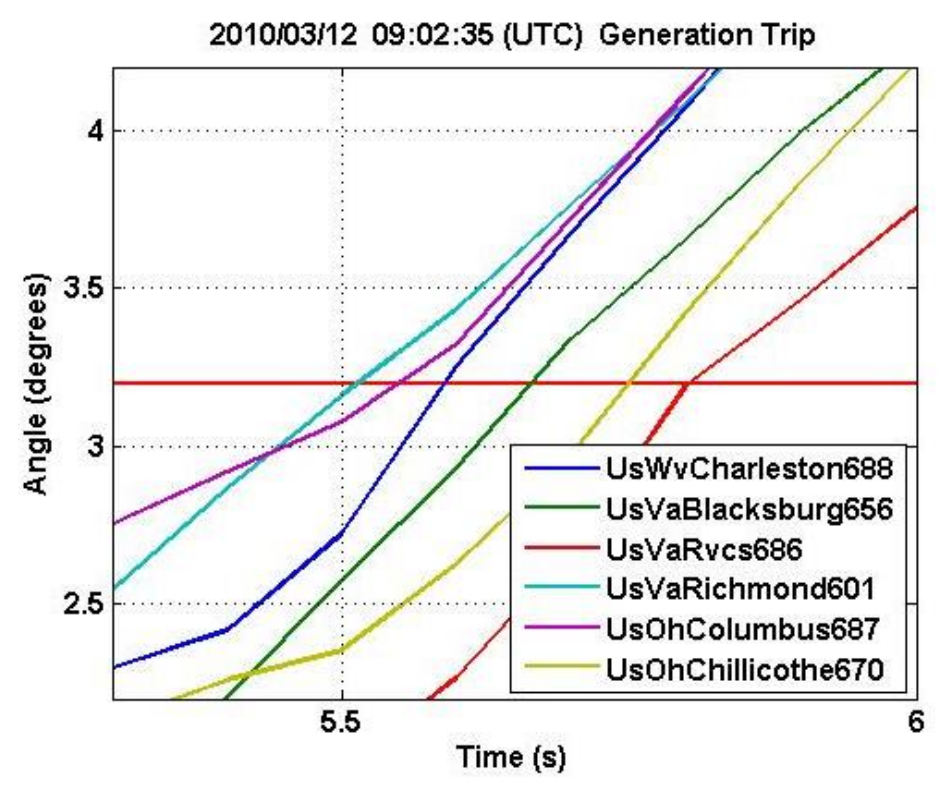

Fig. 2.16. Angle curves of $03 / 12 / 2010$ event with $\pm 0.6^{\circ}$

error. The red horizon line represents the preset threshold.

The triangulation algorithm then failed to obtain the event location because it is out of the 200-mile radius circle around FDR UsVaRichmond601, which is identified as the current first responding FDR. This scenario is shown in Fig. 2.17.

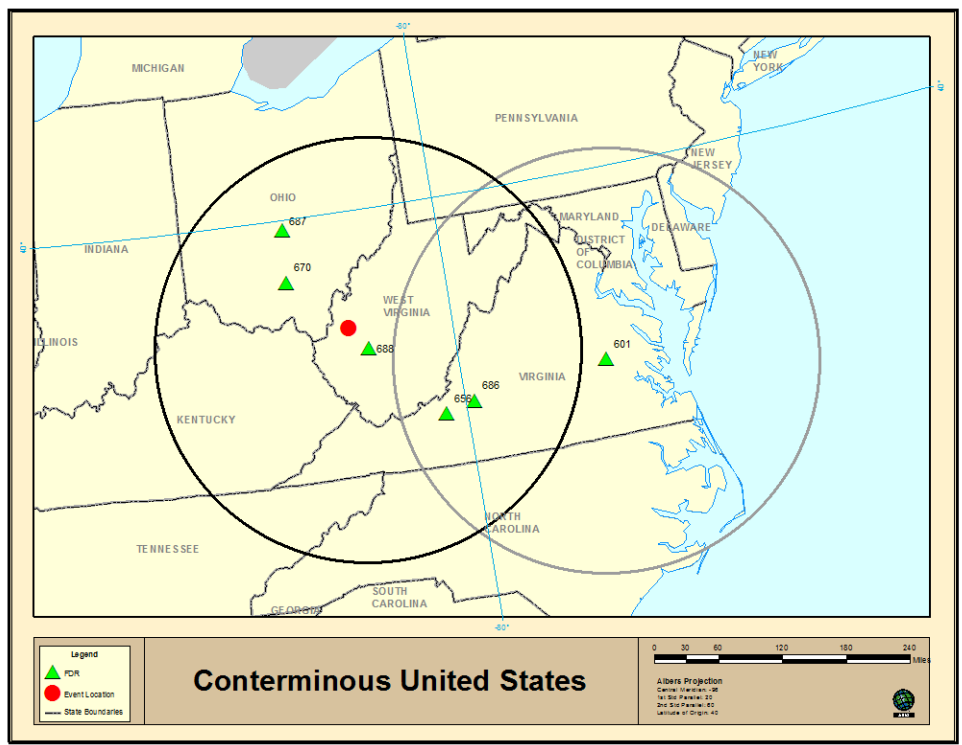

Fig. 2.17. Triangulation failure caused by $1.2^{\circ}$ error. The red circle represents the event location, and the green triangles represent the frequency disturbance recorders. 


\subsection{SUMMARY OF EVENT LOCATION IMPACT}

Angle-based event location is a PMU-based application that uses the phase angle of the power grid to detect and locate the disturbance event. The angle error in most cases does not impact the accuracy of the triangulation algorithm. However, in some cases the angle error is able to cause triangulation failure. Basically, the first responding PMU is the unit most vulnerable to the angle error. According to the cases analyzed above, angle error as low as $\pm 0.1^{\circ}$ can cause a failure, and an angle error of $\pm 0.6^{\circ}$ will have an even greater impact. 


\section{IMPACT ON OSCILLATION DETECTION}

Small signal stability problems with the power grid can potentially cause significant electromechanical oscillations, which may lead to grid reliability issues and potentially large-scale blackouts. PMUs provide high-precision time-synchronized data for oscillation detection. Frequency and phase angle measured by a PMU can be used for oscillation detection. However, the measurement error will affect the detection result, even resulting in its failure. In this section, the phase-angle-based oscillation detection is described first, and the impact of measurement error is analyzed.

\subsection{APPROACH}

Currently, angle measurement from PMUs, instead of frequency measurement, is used for oscillation detection, mainly because angle measurement has a lower signal-to-noise ratio (SNR). Because the phase angle deviation in PMU measurement is the integral of the frequency measurement deviation, an oscillation of small amplitude in frequency can cause the angle to obtain a much higher SNR [2]. Figure 3.1 shows an obvious oscillation that happened in February 2008. As shown, system frequency extends from 59.84 to $60.18 \mathrm{~Hz}$, with a total deviation of about $0.34 \mathrm{~Hz}$. However, the relative phase angle extends from $-30^{\circ}$ to $55^{\circ}$ during the same event, with a total angle deviation of nearly $85^{\circ}$. The resolution obtained from the angle deviation during this oscillation event is much higher than that from the frequency measurement.

The oscillation detection module monitors the incoming phasor data in parallel with the frequency event detection module. The difference is that the oscillation detection module will use the angle data instead of the frequency. To obtain the relative angle deviations, the absolute angle measurements from PMUs are processed by referring to a reference PMU and then the angle value of each PMU is normalized to start from zero by subtracting the angle from the starting angle point of each PMU measurement.

The relative angle remains stable without much deviation when the system is operating in a steady state, though it changes abruptly during events because of the power angle redistribution associated with the event. The relative angles will form a wavy curve during the oscillation. The signature of an event will usually show an oscillation data pattern that has a steep angle rise or drop beyond a certain threshold right after disturbances and then, following the oscillation starting point, the oscillation magnitude (the peakpeak magnitude of a swing) goes beyond a certain limit and the oscillation is sustained for at least one swing. The schematic diagram for this is shown in Fig. 3.2. Here the 5-second span is an empirical value derived from the fact that the frequency of the inter-area oscillation normally ranges from $0.1 \mathrm{~Hz}$ to $1.0 \mathrm{~Hz}$.

Oscillation detection uses the same relative angle values as the event location application. The impact on oscillation detection results is brought about primarily by the random error from the PMU, but the impact of instrumentation channel error can be neutralized. Likewise, the maximum PMU measurement error band is considered as $\pm 0.6^{\circ}$ based on IEEE Std. C37.118.1-2011. 


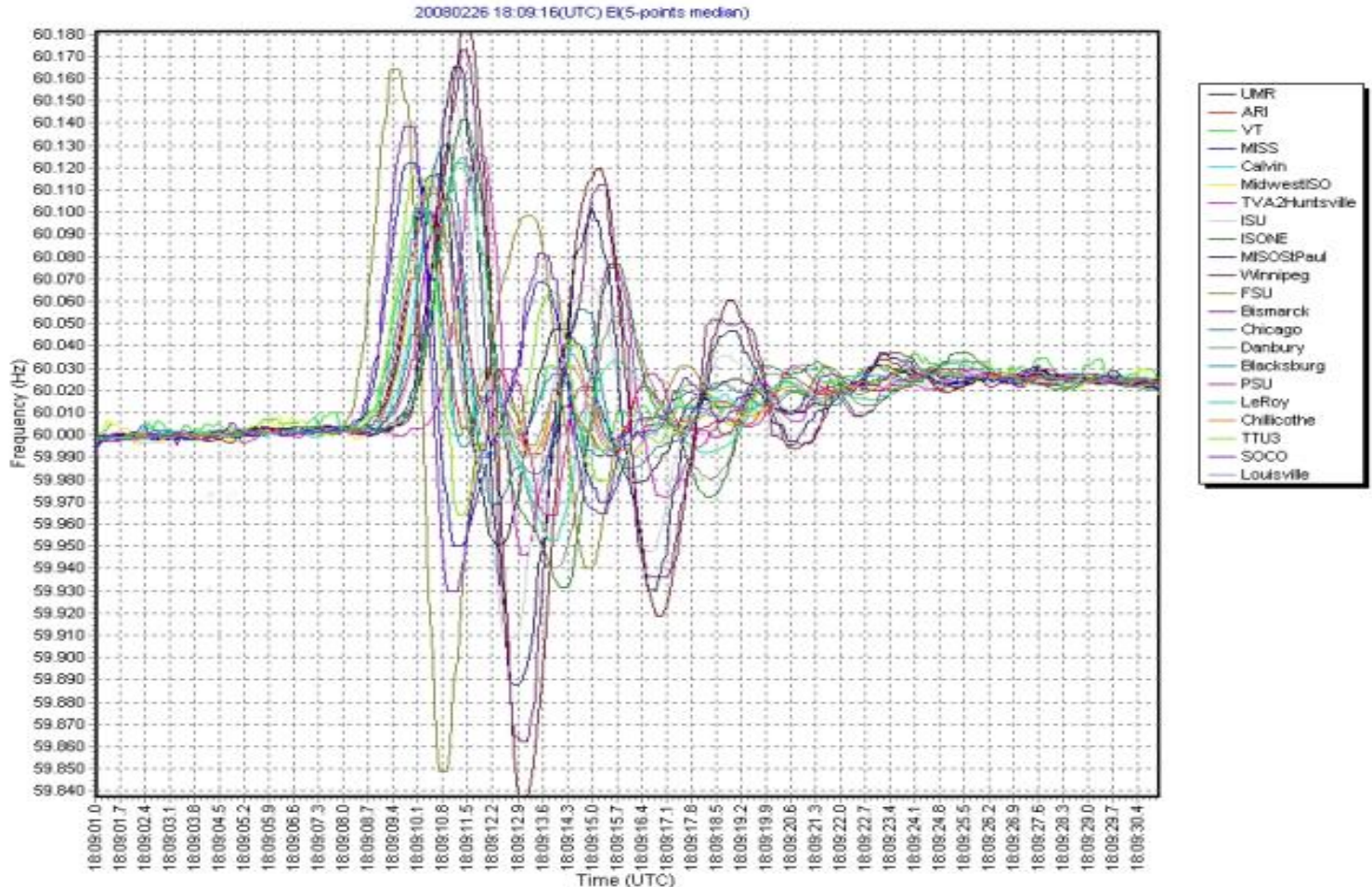

(a) Frequency oscillation monitoring

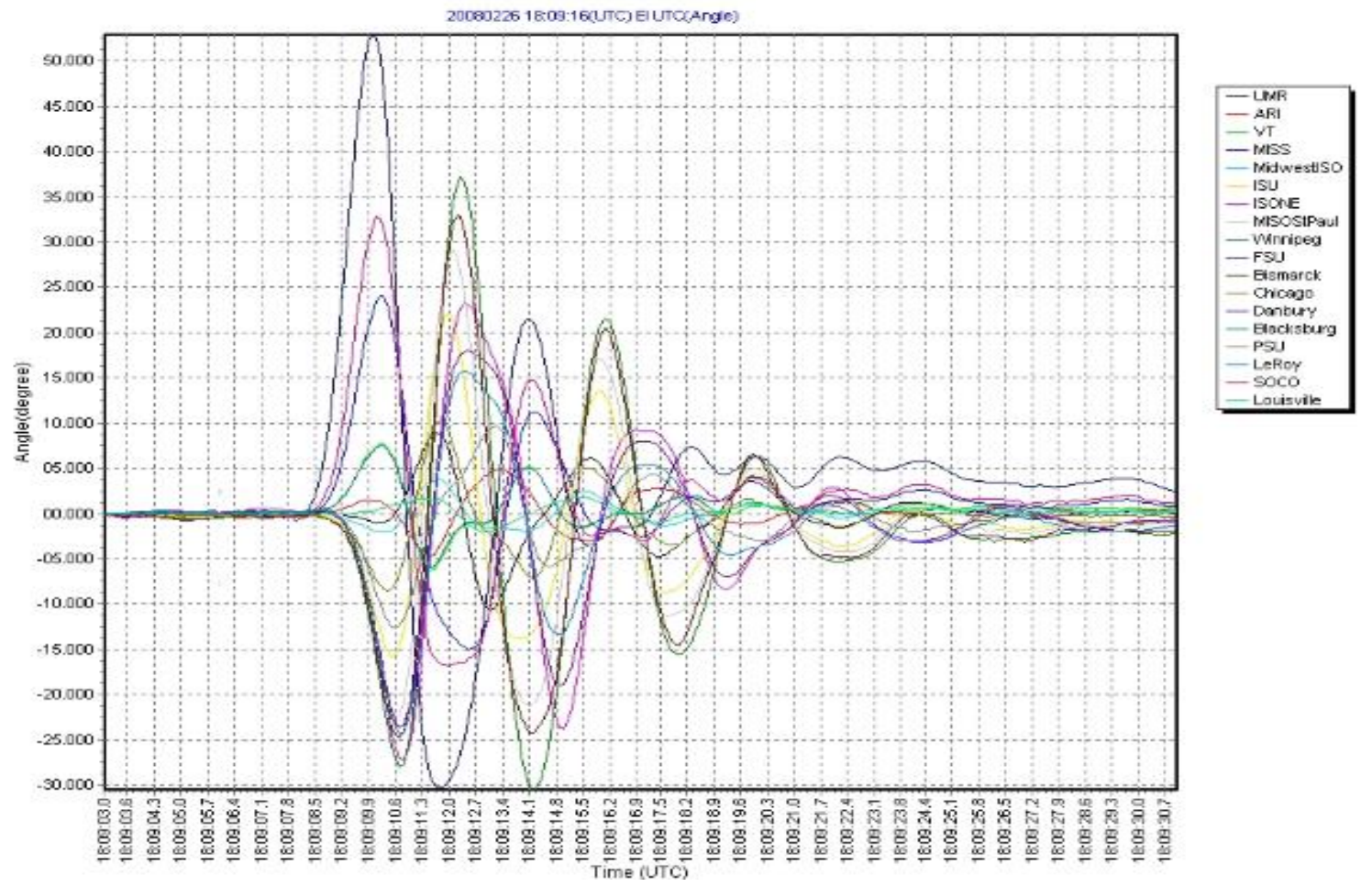

(b) Relative angle oscillation monitoring

Fig. 3.1. Angle measurement vs. frequency measurement in oscillation detection:

(a) frequency oscillation monitoring and (b) relative angle oscillation monitoring by the Frequency Monitoring Network. (Based on an event that occurred in February 2008.) 


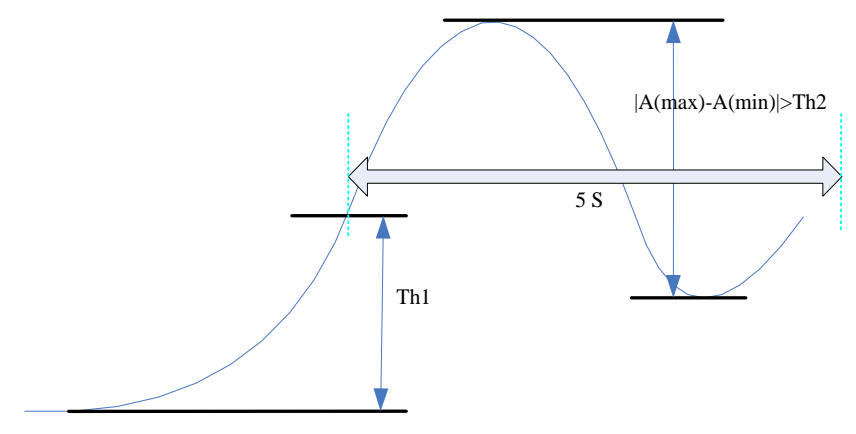

Fig. 3.2. Schematic of the angle-based oscillation detection.

\subsection{RESULTS AND ANALYSIS}

Oscillation detection is based on use of PMU phase angle data. With consideration of PMU data error, oscillation signal detection can be influenced significantly.

Based on the oscillation detection principle, a threshold is set up to determine an oscillation event. If the magnitude (peak to peak magnitude value of a swing) is beyond the threshold, it indicates that the oscillation sustains at least one swing. In this case, the oscillation event would be detected and recorded in the PMU for further analysis. Fig. 3.3 and 3.4 display the impact of PMU system error for a specific threshold. The solid curve represents the pure relative angle data on which oscillation detection should be determined, theoretically.

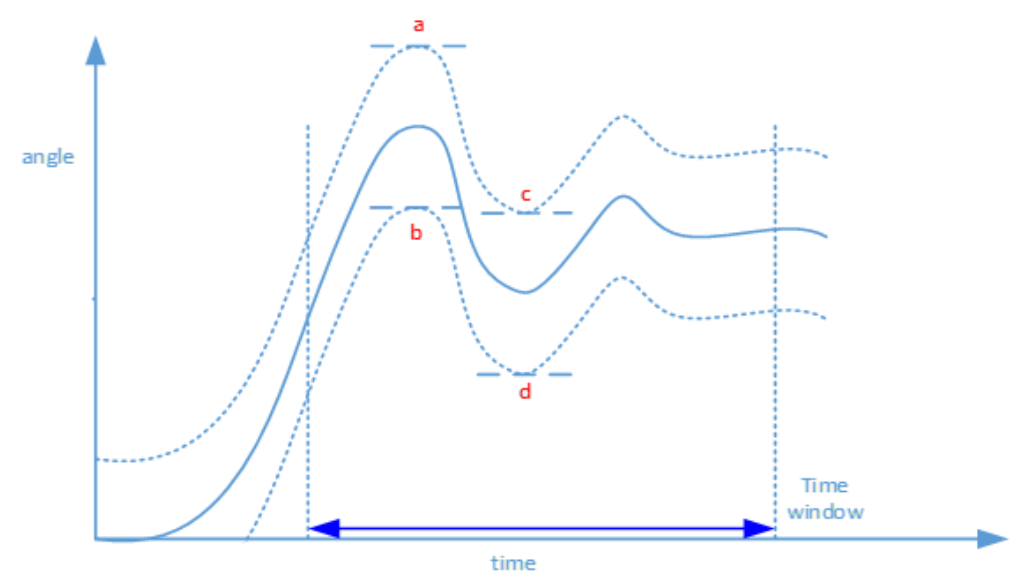

Fig. 3.3. Phasor measurement unit error impact on an oscillation signal. The solid curve represents the pure relative angle data, and the dashed curves represent the relative angle data with $\pm 0.6^{\circ}$ measurement error. Points $a$ and $b$ are peaks of dashed curves, and points $c$ and $d$ are valleys of dashed curves. 


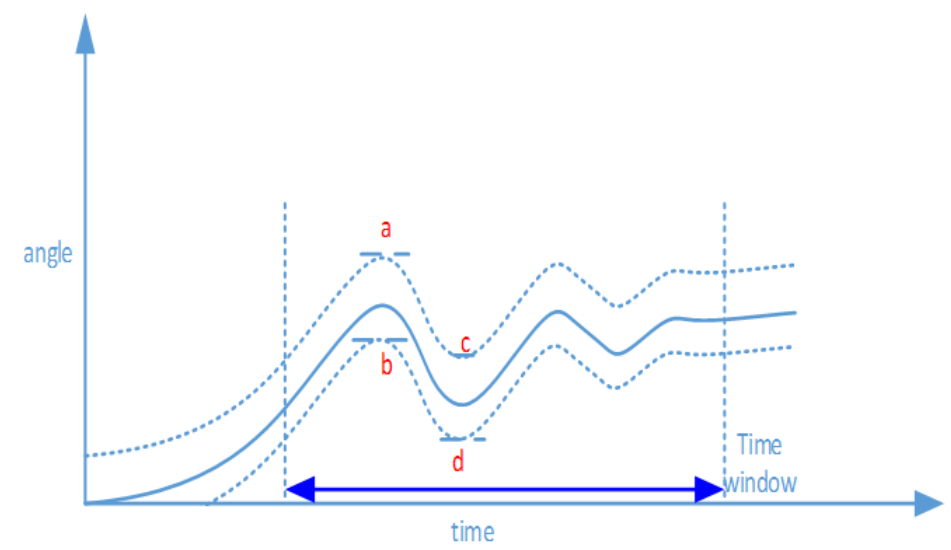

Fig. 3.4. Phasor measurement unit error impact on a nonoscillation signal. The solid curve represents the pure relative angle data, and the dashed curves represent the relative angle data with $\pm 0.6^{\circ}$ measurement error. Point $a$ and $b$ are peaks of dashed curves, and point $c$ and $d$ are valleys of dashed curves.

In Fig. 3.3, the threshold is set to be $3^{\circ}$. The magnitude (peak to peak, P2P) of the solid oscillation curve is $3.1^{\circ}$ and thus beyond the threshold. Theoretically the oscillation should be detected effectively. It is expressed in the following inequality.

\section{$P 2 P>$ threshold}

This oscillation detection module uses relative angle data. It is assumed PMUs in the same interconnection system, including the reference unit, have the same phase angle error range of $0.6^{\circ}$ based on the IEEE Std. C37.118.1-2011. It follows that the range of relative angle error should be from $-1.2^{\circ}$ to $+1.2^{\circ}$, considering the error of the reference unit. When a $\pm 1.2^{\circ}$ error is added to the pure relative angle data, as shown by the dashed curves in Figs. 3.3 and 3.4, there is a possibility that the oscillation signal is covered by error. The plot shows that the maximum magnitude of the signal with error is determined by the discrepancy between points $a$ and $d$, and the minimum magnitude is determined by the discrepancy between points $b$ and $c$. The relationship between these magnitudes and the threshold is shown in Eq. (3.1).

$$
\begin{aligned}
& \max P 2 P=P 2 P_{a d}=P 2 P+2.4>\text { threshold } \\
& \min P 2 P=P 2 P_{b c}=P 2 P-2.4<\text { threshold }
\end{aligned}
$$

According to these relationships, it is obvious that with an error of $\pm 1.2^{\circ}$, the measured magnitude value may be less than the threshold. Only oscillation signals with positive degrees of error and magnitude over the threshold can be certain of detection. PMU system error may result in omitting oscillation detection.

Fig. 3.4 displays the PMU system error impact on a nonoscillation signal. Likewise, the solid curve is the pure relative angle data of the system. The dashed area shows signal with $\pm 2.4^{\circ}$ error. In this plot, the magnitude of the original signal is $\pm 1.2^{\circ}$, less than the threshold of $3.0^{\circ}$. It is a nonoscillation signal. However with error, the result could be influenced. The magnitude is less than the threshold as shown in inequality (3.1) 
As shown in Fig. 3.4, it is highly possible that the magnitude is changed to be the deviation between points $a$ and $d$, the original magnitude with positive $2.4^{\circ}$ error. Finally, the magnitude is changed to be $4.8^{\circ}$, beyond the threshold of $3.0^{\circ}$. This relationship is shown in Eq. (3.2).

$$
\max P 2 P=P 2 P_{a d}=P 2 P+2.4>\text { threshold }
$$

In this case, the nonoscillation signal is detected as an oscillation. Apparently this incorrect detection is influenced by the PMU system error.

The plot in Fig. 3.5 displays PMU system error impact on a real oscillation detection case that happened in the Eastern Interconnection (EI) system at 09:42:07 UTC on August 31, 2014.

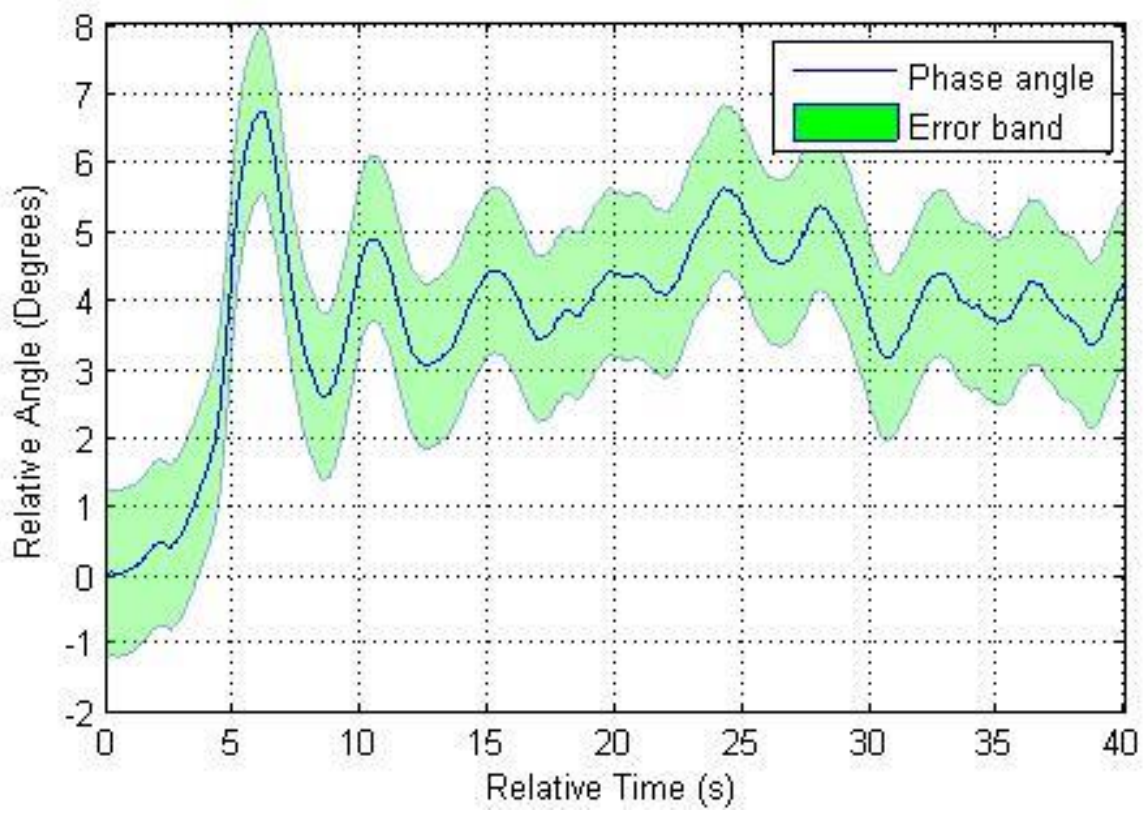

Fig. 3.5. Phasor measurement unit error impact on oscillation signal.

The phase angle data are detected by FDR684 and recorded on the FNET server. For the EI system, the threshold is set up as $3^{\circ}$. Any oscillation should be detected when the magnitude is beyond the threshold; otherwise the system may not be able to recognize it. In the plot in Fig. 3.5 the blue solid curve shows the relative angle above the threshold, of which the magnitude is about $4^{\circ}$. It should be detected as an oscillation event correctly. However, with consideration of $\pm 1.2^{\circ} \mathrm{PMU}$ system error, the magnitude ranges from $1.6^{\circ}$ to $6.5^{\circ}$. When the magnitude is measured below $3^{\circ}$, the oscillation signal is covered by error, which would result in oscillation detection failure.

\subsection{SUMMARY OF OSCILLATION DETECTION IMPACT}

Oscillation detection is a fundamental application based on analysis of relative angle data provided by PMUs. However, unavoidable measurement error influences this application by impacting the magnitude of the signal in a certain range. In some cases, an oscillation signal can be absolutely submerged in error and thus cannot be detected effectively. In other cases, a nonoscillation signal, influenced by error, can be wrongly detected as an oscillation. 



\section{IMPACT ON ISLANDING DETECTION}

DG, which uses fuel cells, micro-hydro, photovoltaics, etc. and is placed close to the load being served, is a new shift in the power industry to take advantage of economic and eco-friendly energy sources [14]. However many issues are involved with DG. One of the main issues is islanding, the situation where a distribution system becomes electrically isolated from the remainder of the power system while continuing to be powered by DG sources. Islanding threatens the safety of line workers and causes the distribution sources to be out of phase with the utility power supply when reclosing. Therefore it is very important to detect islanding quickly and accurately.

PMUs can capture the characteristics of frequency and phase angle change during the islanding generation and could be used for islanding detection. Furthermore, the PMUs network overcomes the limitation of traditional methods such as small mismatch and topology adaptation. Therefore, the application of PMUs in islanding detection is essentially promising.

Because frequency and phase angle are used for this application, their errors may influence the detection precision and results. The islanding detection method studied here is based on the frequency measurement of FNET [15], and the error impact is demonstrated.

\subsection{APPROACH}

In this algorithm, frequency deviation (FD) for all the FDRs is calculated by

$$
F D_{i}(t)=\left|f_{i}(t)-f_{\text {ref }}(t)\right|
$$

where $f_{i}(t)$ is the measured frequency value of the $i$ th FDR at timestamp $t$ and $f_{\text {ref }}(t)$ is defined as the median value of all the monitored FDRs in the same interconnection.

$$
f_{\text {ref }}(t)=\operatorname{median}\left(f_{1}(t), f_{2}(t), \ldots, f_{N}(t)\right)
$$

The integration of frequency deviation (IOFD) is defined as the accumulation of the FD over a certain time period, given by

$$
\operatorname{IOFD}_{i}=\sum_{t=t_{1}}^{t_{2}} F D_{i}(t)
$$

where $t_{1}$ and $t_{2}$ are the start and end times, respectively, for this integration time period. It is used for false event rejection.

When the FD of any FDR surpasses the first period, $F_{t h l}$, an early warning is triggered, indicating possible islanding. Then $I O F D_{i}$ is calculated over a time period and compared to a certain threshold. If it is over the threshold $F_{t h 2}$, it can be determined that the system monitored by this FDR is in off-grid operation. If

not, the system is concluded to not be islanding. For the islanded system, $I O F D_{i}$ is continuously calculated until it falls below the third threshold, $F_{t h 3}$. The whole procedure of islanding detection is shown in Fig. 4.1. 


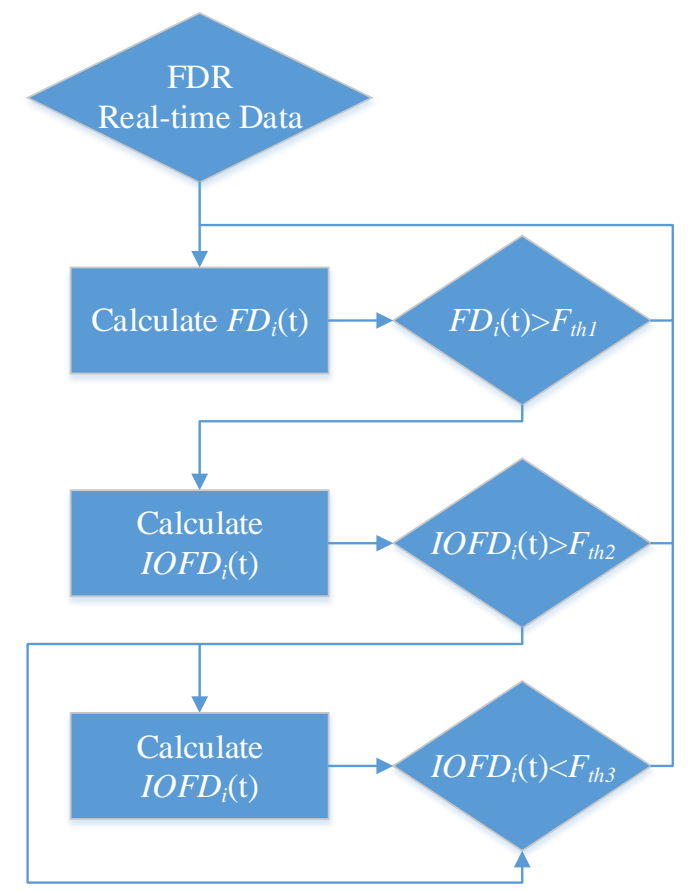

Fig. 4.1. Flow chart of the islanding detection method.

When the frequency angle is mixed with the measurement error, the result of $F D_{i}$ and $I O F D_{i}$ will also be influenced. This may cause the islanding detection method to fail or give a false alarm. To demonstrate this situation, an islanding detection case is selected. Data collected by FDRs are fed into the algorithm to verify the correction of the method. Frequency error is then manually added to the data and the new detection result is compared with the original one to identify the impact caused by measurement error.

\subsection{RESULTS AND ANALYSIS}

The first case studied happened during Hurricane Sandy in 2012. During that time an FDR in Sussex, New Jersey, detected off-grid operation. The frequencies are plotted in Fig. 4.2.

The frequency deviation that triggered the islanding detection is $262.65 \mathrm{mHz}$, and IOFD is $18,204 \mathrm{mHz}$. In the experiment, errors of $\pm 5 \mathrm{mHz}$ are added to the data by trying to decrease frequency deviation between the FDR detecting the islanding and other adjacent FDRs. However, due to the large frequency deviation, the added error could not cause the islanding detection failure. When continuously increasing the frequency error, the algorithm did not fail to detect the islanding until the error reached $0.35 \mathrm{~Hz}$. The frequency plots are shown in Fig. 4.3. 


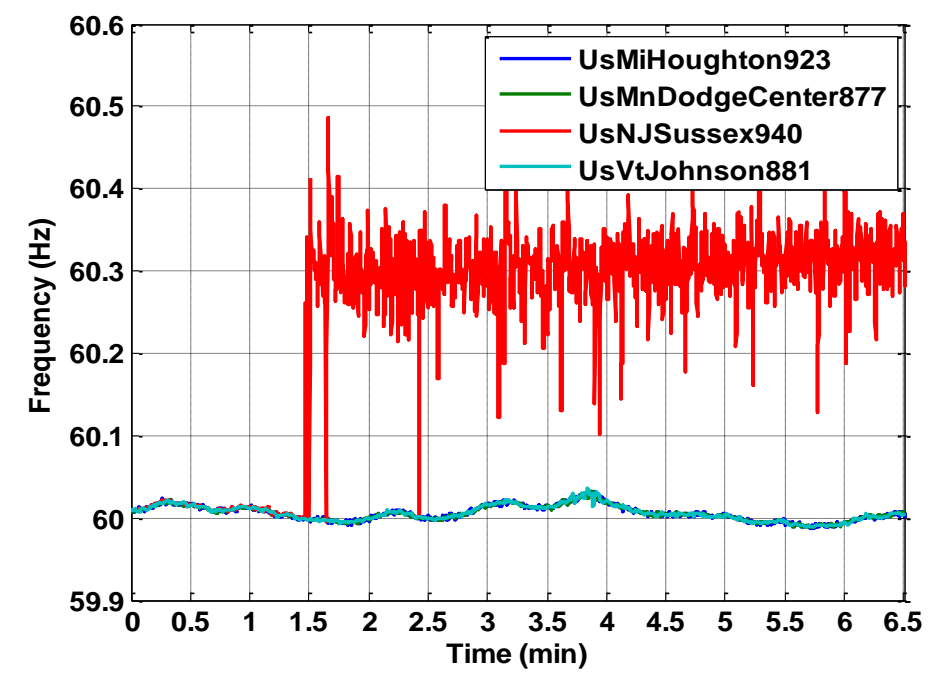

Fig. 4.2. Frequency measured by frequency disturbance recorders in the Hurricane Sandy case.

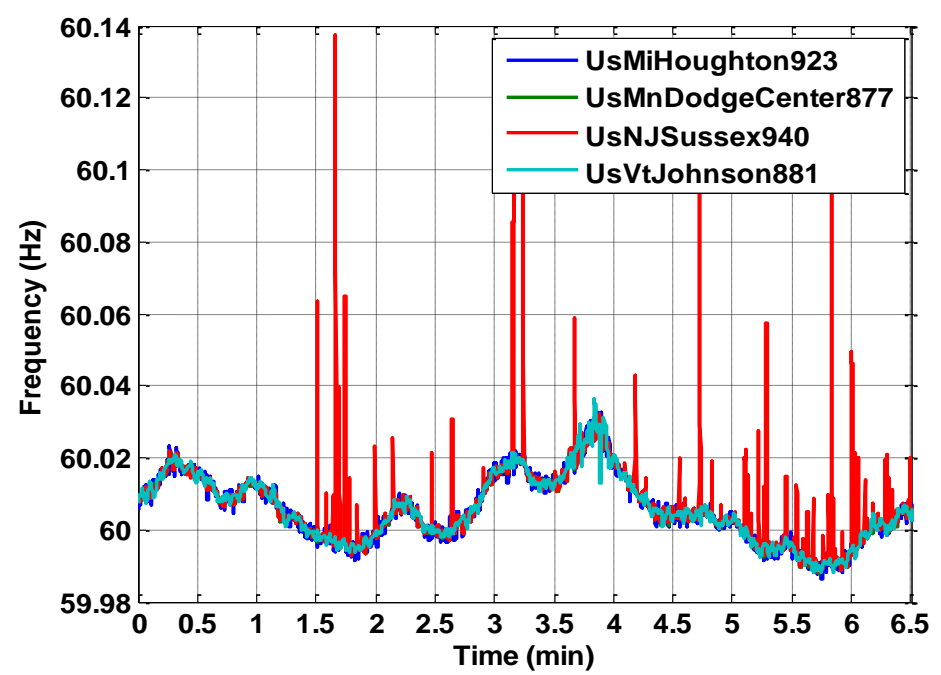

Fig. 4.3. Frequency with $0.35 \mathrm{~Hz}$ error in the Hurricane Sandy case.

An islanding case that occurred in the Western Electricity Coordinating Council (WECC) system of North America on June 1, 2010, was analyzed next. The frequency plots are shown in Fig. 4.4.

Because of the large frequency deviation, the $\pm 5 \mathrm{mHz}$ error does not prevent the islanding detection. Frequency error is increased to $0.2 \mathrm{~Hz}$ before it causes the algorithm failure, as shown in Fig. 4.5. 


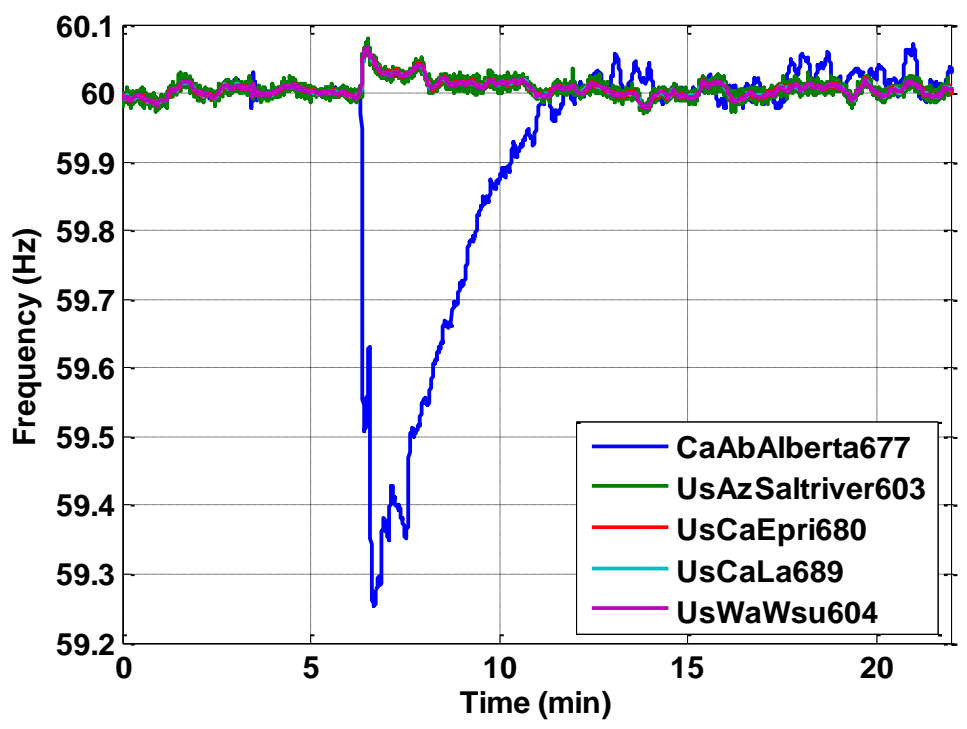

Fig. 4.4. Frequencies measured by frequency disturbance recorders in the 2010/06/01 Western Electricity Coordinating Council islanding case.

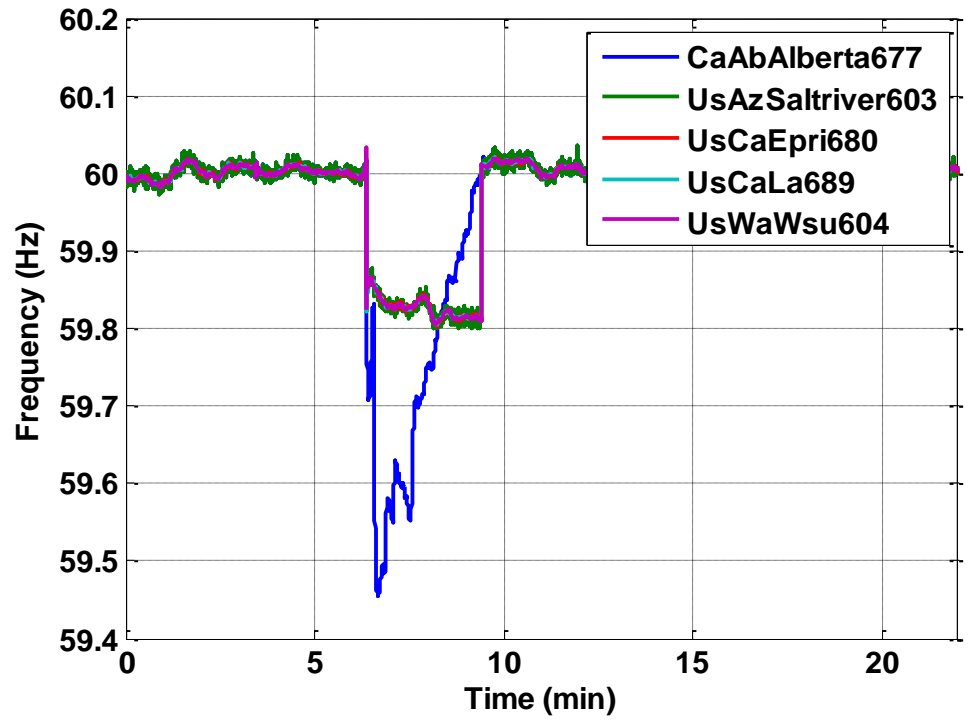

Fig. 4.5. Frequencies with $0.2 \mathrm{~Hz}$ error in the 2010/06/01 Western Electricity Coordinating Council islanding case.

Another islanding case took place in the WECC system on July 22, 2010, as shown in Fig. 4.6. 


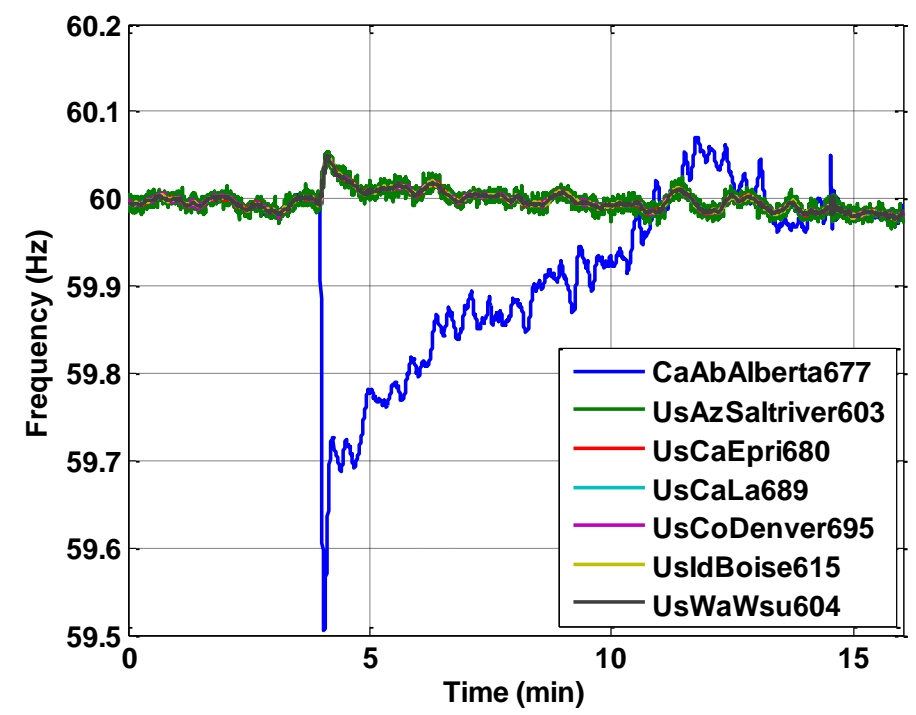

Fig. 4.6. Frequencies measured by frequency disturbance recorders in the 2010/07/22 Western Electricity Coordinating Council islanding case.

According to the simulation, the minimum frequency error that could cause the islanding detection failure is $\pm 0.2 \mathrm{~Hz}$, as seen in Fig. 4.7 .

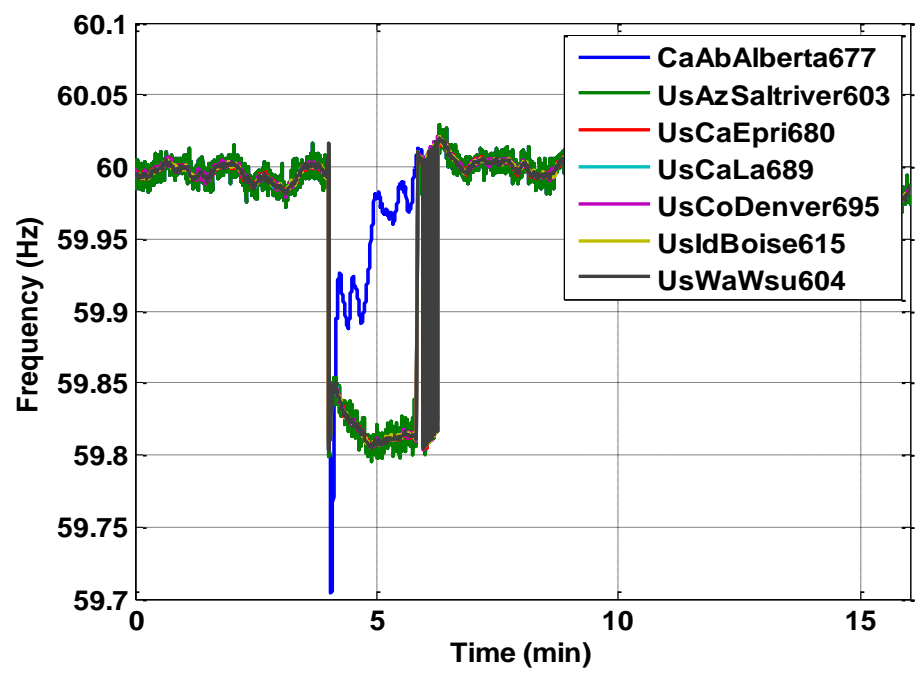

Fig. 4.7. Frequencies with $0.2 \mathrm{~Hz}$ error in the 2010/07/22 Western Electricity Coordinating Council islanding case.

In this case, both the frequency deviation and IOFD are large enough that error within $\pm 5 \mathrm{mHz}$ is unable to cause the islanding detection.

The islanding detection time of this algorithm mainly depends on the integration time for calculating IOFD. According to the testing on the above cases, the $\pm 5 \mathrm{mHz}$ do not influence the detection accuracy 
on detection time of $30 \mathrm{~s}, 4 \mathrm{~s}$, and $2 \mathrm{~s}$. Error may affect the detection accuracy if shorter detection time is required.

\subsection{SUMMARY OF ISLANDING DETECTION IMPACT}

Islanding detection protects the power system with DG from islanding and becoming out of synchronization by monitoring the variation of the frequency, phase angle, impedance, etc. PMU-based islanding detection is capable of obtaining and comparing data over a wide area, thus easily recognizing and locating islanding events. The frequency-measurement-based islanding detection method is not likely to fail through the influence of frequency measurement error. According to the simulation, $\mathrm{a} \pm 5 \mathrm{mHz}$ error is much smaller than the frequency deviation in the islanding area. Typically, only when the frequency error is raised to a few tenths of $1 \mathrm{~Hz}$ can it cause islanding detection failure. Meanwhile, when the required detection time is equal to or above $2 \mathrm{~s}$, it is unlikely to be influenced by the measurement error. 


\section{IMPACT ON DYNAMIC LINE RATING}

The rating of a transmission line indicates the highest current that the line can transfer safely without damaging transmission components or jeopardizing the network's safety, stability, and reliability. Normally the rating is determined by the maximum conductor temperature or the minimum clearance from the conductor to the ground [16]. Several factors also affect a line's rating, such as ambient weather conditions (temperature, wind speed, solar radiation, etc.), conductor size, and resistance.

Traditionally, static line rating (SLR) is widely used by transmission owners and operators. However, SLR relies on the worst weather conditions [e.g., high ambient temperature $\left(40^{\circ} \mathrm{C}\right)$, low wind speed $(0.61 \mathrm{~m} / \mathrm{s})$, and full sun] and is considered too conservative [17].

DLR technology is developed to satisfy the increasing transmission capacity and effectively use the actual capacity of the transmission line. DLR technology monitors the time-varying weather and load conditions. Communication technologies are used to transfer these data to the DLR algorithm, which determines the capacity of the transmission line based on the real-time conditions.

\subsection{APPROACH}

IEEE Standard 738-2012 provides the mathematical equations to define the thermal behavior of the conductor, which can be used to calculate SLR, transient line rating, and DLR.

Up to now, two main methods have been used for real-time monitoring and DLR calculations. One is based on the sag monitor of the transmission line [18]. Alternatively, DLR technology uses PMU measurement data at both ends of the transmission line to calculate DLR [19]. The first method, which doesn't use PMU measurement data, is beyond the scope of this report.

As shown in Fig. 5.1, PMUs are installed on both ends of transmission lines.

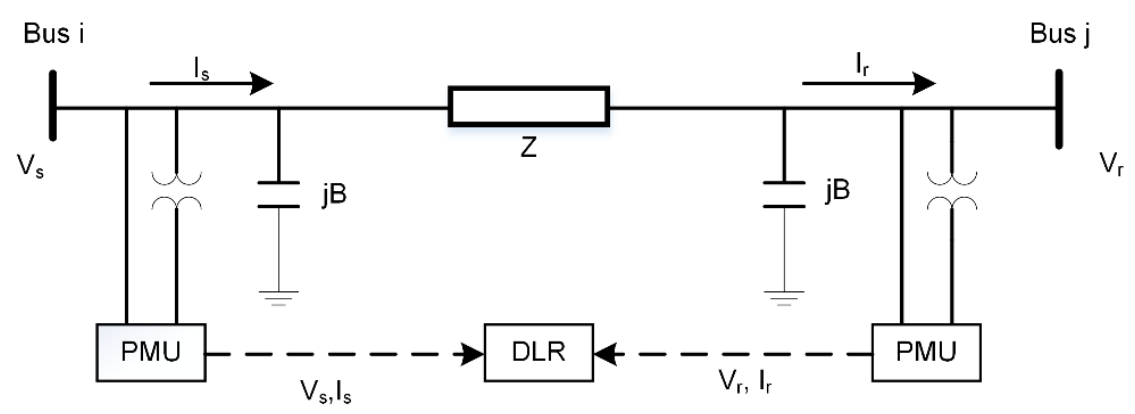

Fig. 5.1. Transmission line with phasor measurement units at both ends.

The voltage and current phasors measured are as follows.

$$
\begin{aligned}
& \bar{V}_{\mathrm{s}}=V_{\mathrm{s}} \angle \alpha_{\mathrm{s}}=V_{\mathrm{s}}\left(\cos \alpha_{\mathrm{s}}+j \sin \alpha_{\mathrm{s}}\right) \\
& \bar{I}_{\mathrm{s}}=I_{\mathrm{s}} \angle \beta_{\mathrm{s}}=I_{\mathrm{s}}\left(\cos \beta_{\mathrm{s}}+j \sin \beta_{\mathrm{s}}\right) \\
& \bar{V}_{\mathrm{r}}=V_{\mathrm{r}} \angle \alpha_{\mathrm{r}}=V_{\mathrm{r}}\left(\cos \alpha_{\mathrm{r}}+j \sin \alpha_{\mathrm{r}}\right) \\
& \bar{I}_{\mathrm{r}}=I_{\mathrm{r}} \angle \beta_{\mathrm{r}}=I_{\mathrm{r}}\left(\cos \beta_{\mathrm{r}}+j \sin \beta_{\mathrm{r}}\right)
\end{aligned}
$$


Measurements with the same time stamp are used to estimate transmission line parameters. The overall framework of the PMU-based DLR technology is shown in Fig. 5.2 (The model is illustrated in Appendix B).

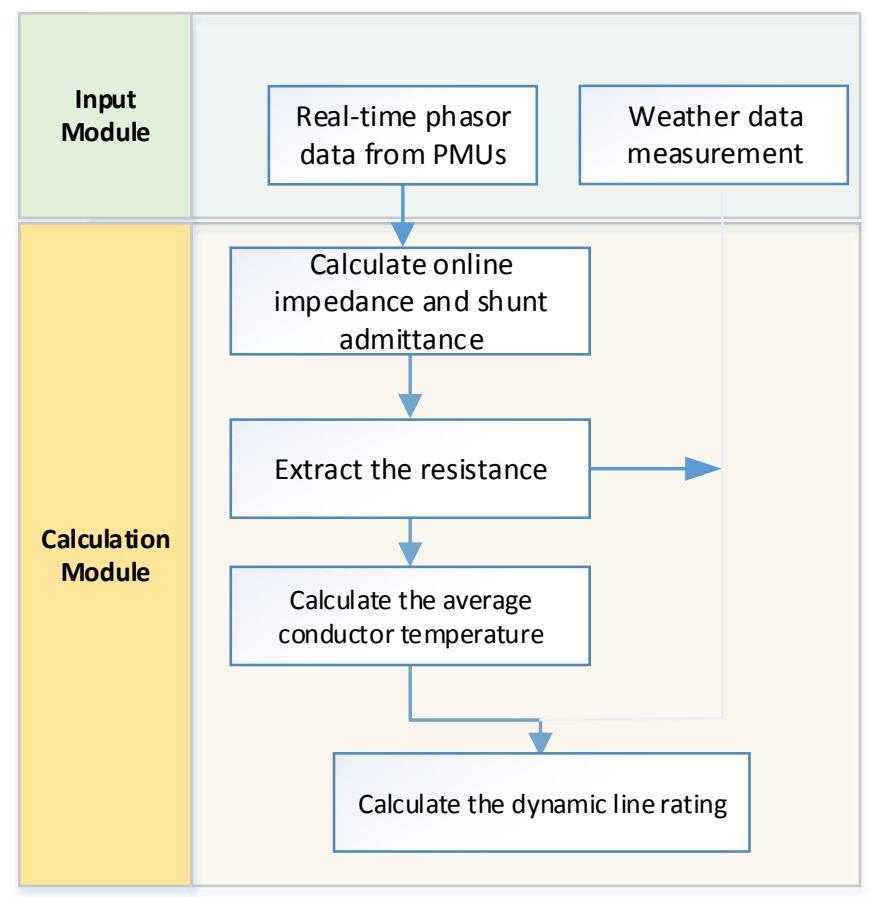

Fig. 5.2. Overall framework of phasor measurement unit (PMU)-based dynamic line rating technology.

The flow chart works as follows.

1. Collect the real-time voltage and current phasor quantities $\left(V_{\mathrm{r}}, I_{\mathrm{r}}, V_{\mathrm{s}}, I_{\mathrm{s}}\right)$ at both ends of the transmission line measured by PMUs.

2. Calculate actual impedance and shunt admittance of the line and extract the resistance.

3. Calculate the average conductor temperature based on the estimated resistance and properties of the conductor material.

4. Measure local weather conditions directly (e.g., wind speed and direction, ambient temperature, sun emission).

5. Calculate DLR in real time by considering estimated resistance, average conductor temperature, and local weather conditions.

The PMU measurement error will induce uncertainty in the estimation of the transmission line parameter due to the analog-to-digital converter (ADC) resolution and the associated computational algorithm [20]. It will raise the error of the estimated average temperature and, consequently, the error of the estimation of DLR. To evaluate the error impact on DLR, error percentage of DLR is defined as

$$
\eta=\frac{I_{\text {max_error }}-I_{\max 0}}{I_{\max 0}} \times 100 \%
$$


where $I_{\max \_ \text {error }}$ is the maximum allowable current calculated with error and $I_{\max 0}$ is the maximum allowable current calculated without error.

\subsection{RESULTS AND ANALYSIS}

The conductor of the transmission line adopts the 26/7 Drake aluminum conductor, steel-reinforced (ACSR). The configuration and the parameters of the conductor are based on IEEE Std. 738-2012. The DLR model in this system is assumed to refresh every $10 \mathrm{~min}$. When incorporating PMU measurements into the DLR calculating model, there are different kinds of errors, such as the PMU buffer, the magnitude error, the angle error, and so on. Only the angle error is considered here as an example. It originates mainly from two parts: PMU and instrumentation channel. For the PMU part, we use $-0.6^{\circ}$ to $+0.6^{\circ}$, which is required by IEEE Std. C37.118.1-2011. The instrumentation channel errors include $\mathrm{CT} / \mathrm{VT} / \mathrm{CCVT}$ and cable, and range from $-1^{\circ}$ to $0^{\circ}$. Notice that $\pm 0.6^{\circ}$ is the maximum error required by the standard. The errors of most commercial PMUs are much less than this value.

\subsubsection{Scenario 1}

To find out the worst case of the PMU measurement error impact, 64 cases are tested, representing the 64 different error directions possible, as shown in Table 5.1. In this scenario, all the cases are carried under the base case (refer to Appendix C.1), which means the time-varied parameters (the wind speed, temperature, solar radiation, load, etc.) are assumed constant. In this base case, DLR without PMU measurement error is $1,192.881 \mathrm{~A}$.

Table 5.1. Phasor measurement unit error impact on dynamic line rating with different error directions

\begin{tabular}{ccccccc}
\hline CASE & $\boldsymbol{\alpha}_{\mathbf{s}}$ & $\boldsymbol{\beta}_{\mathbf{s}}$ & $\boldsymbol{\alpha}_{\mathbf{r}}$ & $\boldsymbol{\beta}_{\mathbf{r}}$ & $\boldsymbol{I}_{\max }(\mathbf{A})$ & $\begin{array}{c}\text { Error } \\
\boldsymbol{\eta}\end{array}$ \\
\hline 1 & -0.4 & -0.4 & -0.4 & -0.4 & 1035.734 & $0.000 \%$ \\
2 & -0.4 & -0.4 & 0.6 & 0.6 & 1017.415 & $-1.769 \%$ \\
3 & -0.4 & -0.4 & -0.4 & -1.6 & 1066.743 & $2.994 \%$ \\
4 & -0.4 & -0.4 & 0.6 & -0.6 & 1027.921 & $-0.754 \%$ \\
5 & -0.4 & -0.4 & -1.6 & -0.4 & 1042.322 & $0.636 \%$ \\
6 & -0.4 & -0.4 & -0.6 & 0.6 & 1022.231 & $-1.304 \%$ \\
7 & -0.4 & -0.4 & -1.6 & -1.6 & 1084.030 & $4.663 \%$ \\
8 & -0.4 & -0.4 & -0.6 & -0.6 & 1041.500 & $0.557 \%$ \\
9 & 0.6 & 0.6 & -0.4 & -0.4 & 1075.094 & $3.800 \%$ \\
10 & 0.6 & 0.6 & 0.6 & 0.6 & 1035.734 & $0.000 \%$ \\
11 & 0.6 & 0.6 & -0.4 & -1.6 & 1119.590 & $8.096 \%$ \\
12 & 0.6 & 0.6 & 0.6 & -0.6 & 1066.743 & $2.994 \%$ \\
13 & 0.6 & 0.6 & -1.6 & -0.4 & 1078.714 & $4.150 \%$ \\
14 & 0.6 & 0.6 & -0.6 & 0.6 & 1042.322 & $0.636 \%$ \\
15 & 0.6 & 0.6 & -1.6 & -1.6 & 1132.424 & $9.335 \%$ \\
16 & 0.6 & 0.6 & -0.6 & -0.6 & 1084.03 & $4.663 \%$ \\
17 & -0.4 & -1.6 & -0.4 & -0.4 & 1065.524 & $2.876 \%$ \\
18 & -0.4 & -1.6 & 0.6 & 0.6 & 1027.396 & $-0.805 \%$ \\
19 & -0.4 & -1.6 & -0.4 & -1.6 & 1102.077 & $6.405 \%$ \\
\hline
\end{tabular}


Table 5.1 (continued)

\begin{tabular}{|c|c|c|c|c|c|c|}
\hline CASE & $\alpha_{\mathrm{s}}$ & $\boldsymbol{\beta}_{\mathrm{s}}$ & $\alpha_{\mathrm{r}}$ & $\boldsymbol{\beta}_{\mathrm{r}}$ & $I_{\max }(\mathrm{A})$ & $\begin{array}{c}\text { Error } \\
\eta\end{array}$ \\
\hline 20 & -0.4 & -1.6 & 0.6 & -0.6 & 1045.998 & $0.991 \%$ \\
\hline 21 & -0.4 & -1.6 & -1.6 & -0.4 & 1082.437 & $4.509 \%$ \\
\hline 22 & -0.4 & -1.6 & -0.6 & 0.6 & 1040.346 & $0.445 \%$ \\
\hline 23 & -0.4 & -1.6 & -1.6 & -1.6 & 1129.509 & $9.054 \%$ \\
\hline 24 & -0.4 & -1.6 & -0.6 & -0.6 & 1075.419 & $3.832 \%$ \\
\hline 25 & 0.6 & -0.6 & -0.4 & -0.4 & 1118.025 & $7.945 \%$ \\
\hline 26 & 0.6 & -0.6 & 0.6 & 0.6 & 1065.524 & $2.876 \%$ \\
\hline 27 & 0.6 & -0.6 & -0.4 & -1.6 & 1168.466 & $12.815 \%$ \\
\hline 28 & 0.6 & -0.6 & 0.6 & -0.6 & 1102.077 & $6.405 \%$ \\
\hline 29 & 0.6 & -0.6 & -1.6 & -0.4 & 1130.455 & $9.145 \%$ \\
\hline 30 & 0.6 & -0.6 & -0.6 & 0.6 & 1082.437 & $4.509 \%$ \\
\hline 31 & 0.6 & -0.6 & -1.6 & -1.6 & 1192.881 & $15.173 \%$ \\
\hline 32 & 0.6 & -0.6 & -0.6 & -0.6 & 1129.509 & $9.054 \%$ \\
\hline 33 & -1.6 & -0.4 & -0.4 & -0.4 & 1013.654 & $-2.132 \%$ \\
\hline 34 & -1.6 & -0.4 & 0.6 & 0.6 & 1019.849 & $-1.534 \%$ \\
\hline 35 & -1.6 & -0.4 & -0.4 & -1.6 & 1015.760 & $-1.929 \%$ \\
\hline 36 & -1.6 & -0.4 & 0.6 & -0.6 & 1015.054 & $-1.997 \%$ \\
\hline 37 & -1.6 & -0.4 & -1.6 & -0.4 & 1013.721 & $-2.125 \%$ \\
\hline 38 & -1.6 & -0.4 & -0.6 & 0.6 & 1016.007 & $-1.905 \%$ \\
\hline 39 & -1.6 & -0.4 & -1.6 & -1.6 & 1020.090 & $-1.510 \%$ \\
\hline 40 & -1.6 & -0.4 & -0.6 & -0.6 & 1013.643 & $-2.133 \%$ \\
\hline 41 & -0.6 & 0.6 & -0.4 & -0.4 & 1017.913 & $-1.721 \%$ \\
\hline 42 & -0.6 & 0.6 & 0.6 & 0.6 & 1013.654 & $-2.132 \%$ \\
\hline 43 & -0.6 & 0.6 & -0.4 & -1.6 & 1031.406 & $-0.418 \%$ \\
\hline 44 & -0.6 & 0.6 & 0.6 & -0.6 & 1015.760 & $-1.929 \%$ \\
\hline 45 & -0.6 & 0.6 & -1.6 & -0.4 & 1018.909 & $-1.624 \%$ \\
\hline 46 & -0.6 & 0.6 & -0.6 & 0.6 & 1013.721 & $-2.125 \%$ \\
\hline 47 & -0.6 & 0.6 & -1.6 & -1.6 & 1037.907 & $0.210 \%$ \\
\hline 48 & -0.6 & 0.6 & -0.6 & -0.6 & 1020.090 & $-1.510 \%$ \\
\hline 49 & -1.6 & -1.6 & -0.4 & -0.4 & 1015.589 & $-1.945 \%$ \\
\hline 50 & -1.6 & -1.6 & 0.6 & 0.6 & 1015.174 & $-1.985 \%$ \\
\hline 51 & -1.6 & -1.6 & -0.4 & -1.6 & 1023.557 & $-1.176 \%$ \\
\hline 52 & -1.6 & -1.6 & 0.6 & -0.6 & 1013.600 & $-2.137 \%$ \\
\hline 53 & -1.6 & -1.6 & -1.6 & -0.4 & 1019.687 & $-1.549 \%$ \\
\hline 54 & -1.6 & -1.6 & -0.6 & 0.6 & 1013.617 & $-2.135 \%$ \\
\hline 55 & -1.6 & -1.6 & -1.6 & -1.6 & 1035.734 & $0.000 \%$ \\
\hline 56 & -1.6 & -1.6 & -0.6 & -0.6 & 1017.415 & $-1.769 \%$ \\
\hline 57 & -0.6 & -0.6 & -0.4 & -0.4 & 1030.819 & $-0.475 \%$ \\
\hline
\end{tabular}


Table 5.1 (continued)

\begin{tabular}{ccccccc}
\hline CASE & $\boldsymbol{\alpha}_{\mathbf{s}}$ & $\boldsymbol{\beta}_{\mathbf{s}}$ & $\boldsymbol{\alpha}_{\mathbf{r}}$ & $\boldsymbol{\beta}_{\mathbf{r}}$ & $\boldsymbol{I}_{\max }(\mathbf{A})$ & $\begin{array}{c}\text { Error } \\
\boldsymbol{\eta}\end{array}$ \\
\hline 58 & -0.6 & -0.6 & 0.6 & 0.6 & 1015.589 & $-1.945 \%$ \\
59 & -0.6 & -0.6 & -0.4 & -1.6 & 1057.063 & $2.059 \%$ \\
60 & -0.6 & -0.6 & 0.6 & -0.6 & 1023.557 & $-1.176 \%$ \\
61 & -0.6 & -0.6 & -1.6 & -0.4 & 1037.020 & $0.124 \%$ \\
62 & -0.6 & -0.6 & -0.6 & 0.6 & 1019.687 & $-1.549 \%$ \\
63 & -0.6 & -0.6 & -1.6 & -1.6 & 1075.094 & $3.800 \%$ \\
64 & -0.6 & -0.6 & -0.6 & -0.6 & 1035.734 & $0.000 \%$ \\
\hline
\end{tabular}

Bolding indicates worst case.

Table 5.1 shows the estimated maximum allowable currents (DLRs) and their error percentages under 64 different cases (each phase angle $\pm 1.2^{\circ}$ ). Case 31 (bolded) is the worst case during these situations. In this case, the DLR is $1,192.881 \mathrm{~A}$, and the maximum relative error reaches as high as $15.173 \%$.

From the last column, it can be seen that the error percentage can be positive or negative, which means, considering the PMU error, the estimation of DLR sometimes appears more conservative and sometimes more optimistic.

In cases 1 and 64, the relative error is zero. This is because when all the angle errors increase or decrease in the same direction with the same value, they are deducted from each other, resulting in a zero DLR error.

\subsubsection{Scenario 2}

The estimation of DLR error is also evaluated under various weather conditions as weather conditions highly affect the rating. The following study shows a DLR error band under different weather conditions (summer and winter). (See Appendix C.3 for details of the weather conditions.)

Figure 5.3 shows a 1-day DLR in summer. The red-circle line stands for the DLR without the PMU measurement error, and the red shadow represents the DLR error band. The green, brown, and pink dashed curves are the temperature, wind speed, and solar heat gain, respectively.

Fig. 5.3 shows the relative error of DLR varies as the weather changes. The maximum error is $45.87 \%$, which is even higher than the maximum value in scenario 1 .

Similarly, Fig. 5.4 shows the angle error impact on DLR on 1 day in winter.

In Fig. 5.4, the blue-circle line represents the DLR without the PMU measurement error in winter and the blue shadow is the DLR error band. In this case, the maximum error is $22.87 \%$. Compared with the summer situation in Fig. 5.4, the average DLR of the line in winter is higher than in summer.

Both these cases give examples that show roughly how much a maximum PMU error affects the estimation of DLR under different weather conditions. It should be noted that these examples are not intended to give a specific DLR error boundary. The DLR system may induce the error by two stages: data collection and DLR calculation. Any improvement for either of these stages has the potential to reduce the error percentage (e.g., using average input of PMU data from the sensors to reduce the impact of measurement error). 


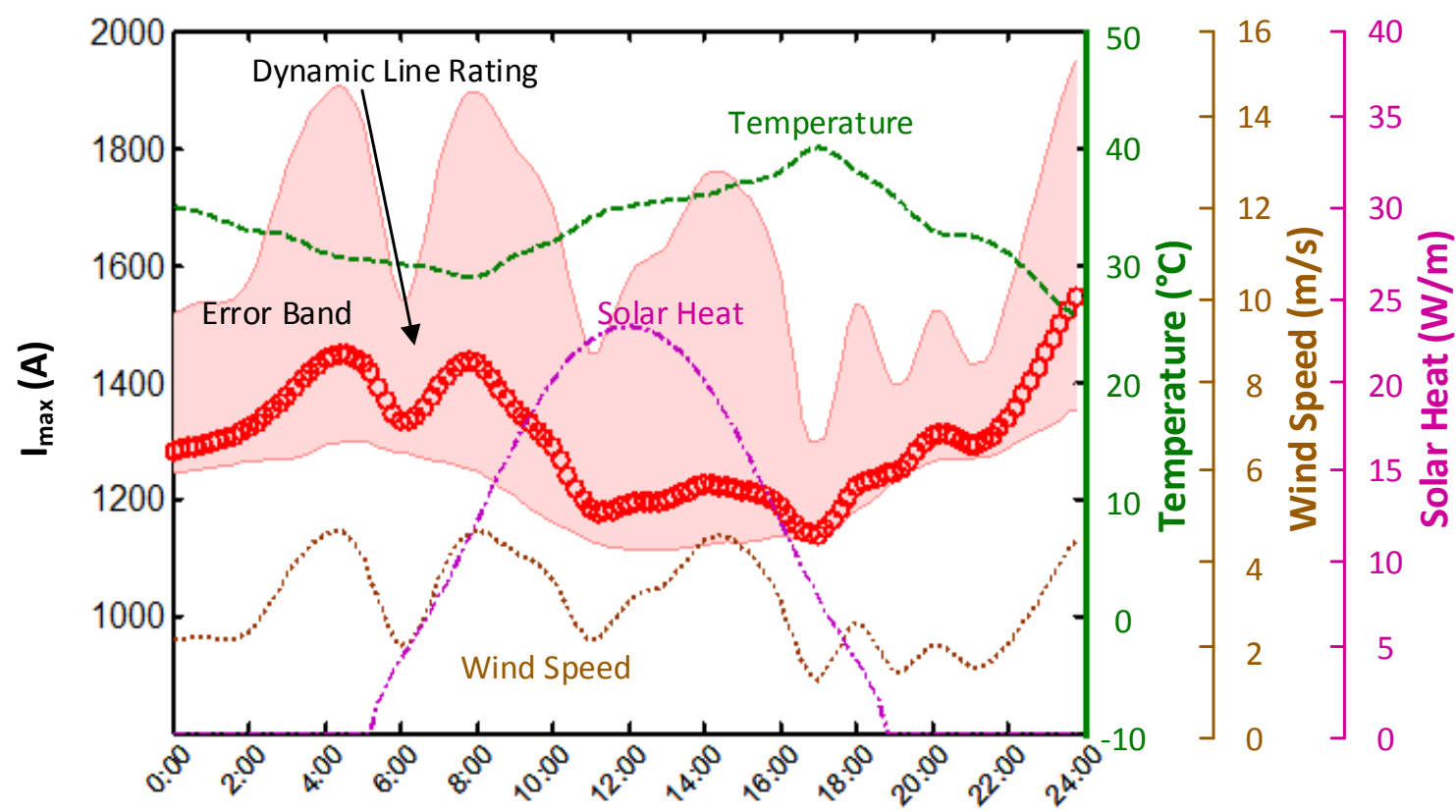

Time of the Day

Fig. 5.3. Dynamic line rating error on 1 day in summer.

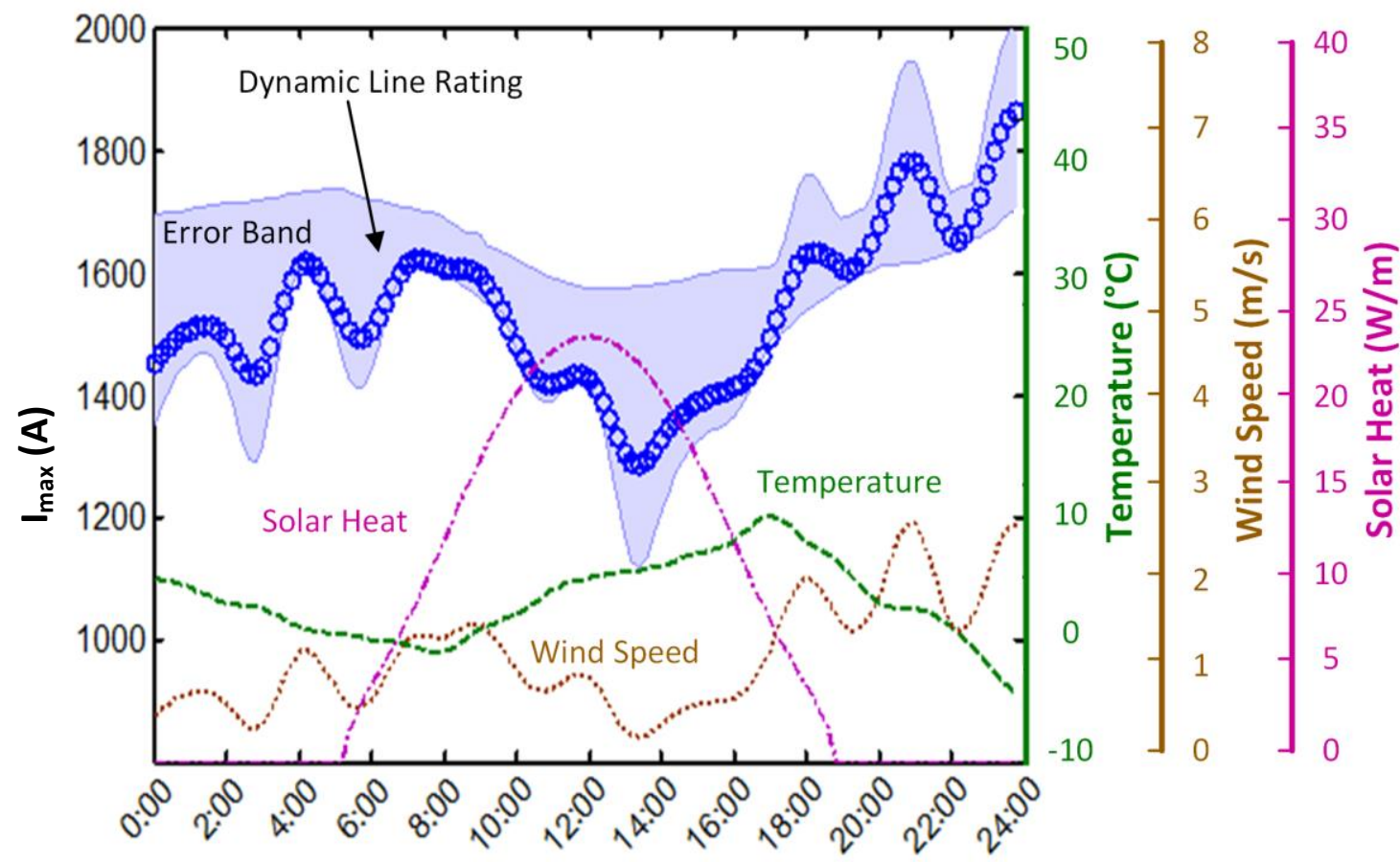

Time of the Day

Fig. 5.4. Dynamic line rating error on 1 day in winter. 


\subsubsection{Scenario 3}

DLR is associated with many factors, such as temperature, wind speed, and solar heat gain. To determine how those factors affect estimation errors, different tests are carried out: (a) keep the temperature $\left(40^{\circ} \mathrm{C}\right)$ and solar heat gain $(23.15 \mathrm{w} / \mathrm{m})$ fixed and change the wind speed, (b) keep the solar heat gain and wind speed $(0.61 \mathrm{~m} / \mathrm{s})$ fixed and change the temperature, and (c) keep the temperature and wind speed fixed and change the solar heat gain. The results are shown in Fig. 5.5.

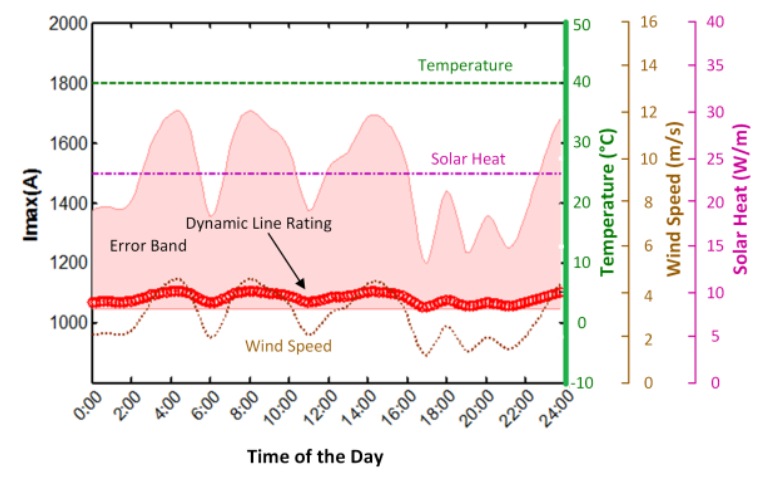

(a) Impact of wind speed on dynamic line rating error

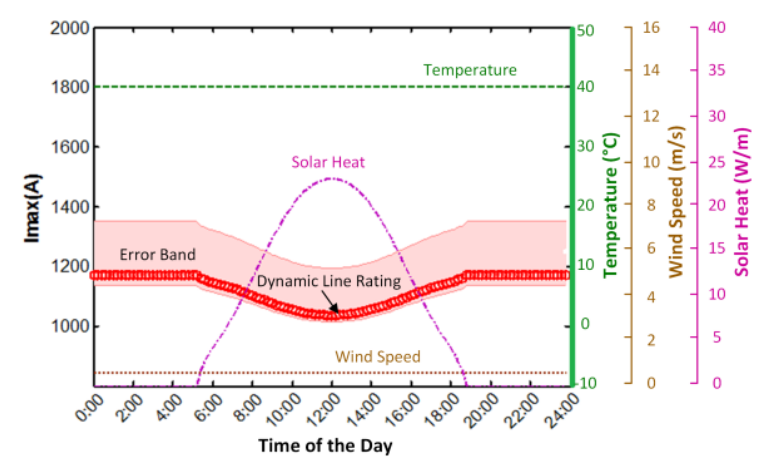

(c) Impact of solar heat on dynamic line rating error

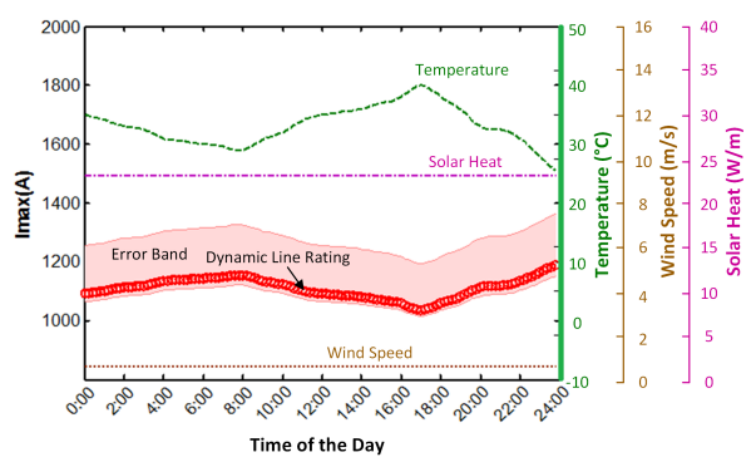

(b) Impact of temperature on dynamic line rating error

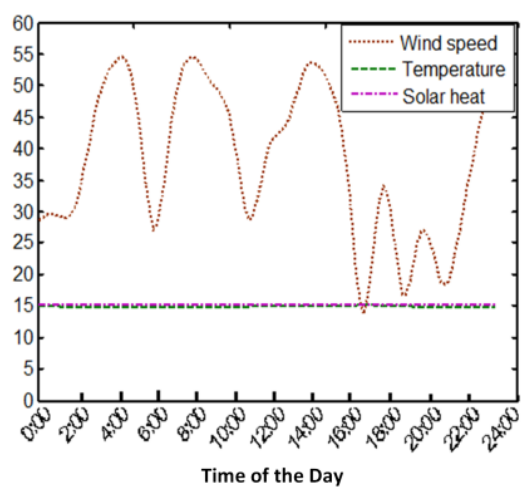

(d) Comparison of the error brought by three impact factors

Fig. 5.5. Impact of wind speed, temperature, and solar heat gain on dynamic line rating error:

(a) impact of wind speed on dynamic line rating error, (b) impact of temperature on dynamic line rating error, (c) impact of solar heat on dynamic line rating error, and (d) comparison of the error brought by three impact factors.

Fig. 5.5(a) shows that when the wind speed goes up, both the DLR and maximum error increase; when the wind speed goes down, both the DLR and the maximum error decrease. In the same manner, Fig. 5.5(b) and (c) show that the temperature and solar heat have the opposite effect on the DLR and maximum error. Fig. 5.5(d) shows the relationship between the error percentage and the parameters that correspond to wind speed changes, temperature changes, and solar heat changes. The figure illustrates that maximum estimation error percentage is sensitive to the wind speed, while it is not sensitive to the temperature and solar heat gain. 


\subsection{SUMMARY OF DYNAMIC LINE RATING IMPACT}

PMU measurement data at both ends of the transmission line can be used to calculate DLR. The phase angle errors at both ends can induce a relatively huge error in the estimation of DLR. The maximum estimation error percentage is sensitive to wind speed but not to temperature and solar heat gain.

It should be noted that in this study the phase angle error includes both $\pm 0.6^{\circ} \mathrm{PMU}$ error and $-1^{\circ}$ to $0^{\circ}$ instrumentation channel error. For real commercial PMUs, the phase angle errors are smaller than $\pm 0.6^{\circ}$; therefore the errors of DLR are also smaller. If the angle errors from instrumentation channels are compensated by calibration, the errors of DLR will decrease further. Meanwhile, some improved calculation algorithms may have the potential to reduce the error impact and need to be studied further.

The transmission system must become more flexible as new renewable and natural gas generation enters the grid. DLR technology is inexpensive to install and operationally flexible, making it an attractive alternative to more costly transmission system upgrades. 


\section{CONCLUSION}

In this report, the impact of synchrophasor measurement error on several applications is analyzed. The results are included in Table 6.1

Table 6.1. Effect of measurement error on applications

\begin{tabular}{|c|c|c|}
\hline Application & Effect & Significance \\
\hline Event location & A small number of cases show impact & Minor impact typically \\
\hline Oscillation detection & Possible failure detection or false alarm & Threshold dependent \\
\hline Islanding detection & $\begin{array}{l}\text { Not likely to be influenced for detection time } \\
\text { above } 2 \mathrm{~s}\end{array}$ & Detection time dependent \\
\hline Dynamic line rating & Potential to induce huge error. & Very sensitive \\
\hline
\end{tabular}

It can be seen from the table that the DLR application is more likely to be influenced by measurement error. It is possible for the oscillation to be submerged by the error, resulting in detection failure. It is also possible for a nonoscillation to be reported as a result of error. Both depend on the threshold. For islanding detection, when the required detection time is equal to or above $2 \mathrm{~s}$, it is unlikely to be influenced by the measurement error. For event location, the error in most cases is not likely to impact the result.

The PMU errors used in this study are taken from IEEE Std. C37.118.1-2011 as the minimum required for PMUs. We need to point out that many commercial PMUs, as well as the FDRs from UTK/ORNL, have a much higher level of accuracy. For example, one commercial PMU we tested has an angle accuracy of 0.005 degree and frequency accuracy of $0.1 \mathrm{mHz}$. The UTK/ORNL FDR has an angle accuracy of 0.005 degree and frequency accuracy of $0.06 \mathrm{mHz}$. In a future study, it may be more realistic to use typical industry accuracy levels for an assessment. 



\section{REFERENCES}

[1] Y. Ye, "Wide-area Situational Awareness Application Developments," Doctor of Philosophy, Electrical Engineering and Computer Science, The University of Tennessee, Knoxville, Knoxville TN, 2011.

[2] T. Xia, Y. Zhang, L. Chen, Z. Yuan, P. N. Markham, Y. Ye, et al., "Phase angle-based power system inter-area oscillation detection and modal analysis," European Transactions on Electrical Power, vol. 21, pp. 1629-1639, 2011.

[3] T. Funabashi, K. Koyanagi, and R. Yokoyama, "A review of islanding detection methods for distributed resources," in Power Tech Conference Proceedings, 2003 IEEE Bologna, 2003, p. 6 pp. Vol.2.

[4] J. Sung-Il and K. Kwang-Ho, "An islanding detection method for distributed generations using voltage unbalance and total harmonic distortion of current," Power Delivery, IEEE Transactions on, vol. 19, pp. 745-752, 2004.

[5] L. Zhenzhi, X. Tao, Y. Yanzhu, Z. Ye, C. Lang, L. Yilu, et al., "Application of wide area measurement systems to islanding detection of bulk power systems," Power Systems, IEEE Transactions on, vol. 28, pp. 2006-2015, 2013.

[6] D. A. Douglass and A. Edris, "Real-time monitoring and dynamic thermal rating of power transmission circuits," Power Delivery, IEEE Transactions on, vol. 11, pp. 1407-1418, 1996.

[7] R. Mai, L. Fu, and H. Xu, "Dynamic Line Rating estimator with synchronized phasor measurement," in Advanced Power System Automation and Protection (APAP), 2011 International Conference on, 2011, pp. 940-945.

[8] "IEEE Standard for Synchrophasor Measurements for Power Systems," vol. C37.118, ed. New York: IEEE Std, 2011.

[9] A. P. S. Meliopoulos, G. J. Cokkinides, F. Galvan, and B. Fardanesh, "GPS-Synchronized Data Acquisition: Technology Assessment and Research Issues," in System Sciences, 2006. HICSS '06. Proceedings of the 39th Annual Hawaii International Conference on, 2006, pp. 244c-244c.

[10] A. P. Meliopoulos, V. Madani, D. Novosel, G. Cokkinides, R. Alaileh, B. Fardanesh, et al., "Synchrophasor Measurement Accuracy Characterization," North American Synchrophasor Initiative Performance \& Standards Task Team2007.

[11] J. S. Thorp, C. E. Seyler, and A. G. Phadke, "Electromechanical wave propagation in large electric power systems," Circuits and Systems I: Fundamental Theory and Applications, IEEE Transactions on, vol. 45, pp. 614-622, 1998.

[12] Z. Yingchen, P. Markham, X. Tao, C. Lang, Y. Yanzhu, W. Zhongyu, et al., "Wide-Area Frequency Monitoring Network (FNET) Architecture and Applications," Smart Grid, IEEE Transactions on, vol. 1, pp. 159-167, 2010.

[13] R. M. Gardner, Y. Liu, and Z. Zhong, "Location determination of power system disturbances based on frequency responses of the system," 2010.

[14] P. Mahat, C. Zhe, and B. Bak-Jensen, "Review of islanding detection methods for distributed generation," in Electric Utility Deregulation and Restructuring and Power Technologies, 2008. DRPT 2008. Third International Conference on, 2008, pp. 2743-2748.

[15] J. Guo, Y. Zhang, M. A. Young, M. J. Till, A. Dimitrovski, Y. Liu, et al., "Design and Implementation of a Real-Time Off-Grid Operation Detection Tool from a Wide-Area Measurements Perspective," Smart Grid, IEEE Transactions on, vol. PP, pp. 1-1, 2014. 
[16] U. S. D. o. Energy, "Dynamic Line Rating Systems for Transmission Lines," 2014.

[17] IEEE, "IEEE Standard for Calculating the Current-Temperature Relationship of Bare Overhead Conductors," vol. IEEE Std 738-1993, ed, 1993.

[18] N. A. E. R. Corporation, "Real-Time Application of Synchrophasors for Improving Reliability," 2010.

[19] "Line Thermal Monitoring-dynamic rating of transmission lines," in A PSGuard Wide Area Monitoring System application, ed.

[20] S. Chakrabarti, E. Kyriakides, and M. Albu, "Uncertainty in Power System State Variables Obtained Through Synchronized Measurements," Instrumentation and Measurement, IEEE Transactions on, vol. 58, pp. 2452-2458, 2009.

[21] "TI GPS PPS Timing Application Note," Texas Instruments2012.

[22] L. Hsiung Cheng, "Intelligent Neural Network-Based Fast Power System Harmonic Detection," Industrial Electronics, IEEE Transactions on, vol. 54, pp. 43-52, 2007. 
APPENDIX A. APPLICATIONS OF PHASOR MEASUREMENT UNITS 



\section{APPENDIX A. APPLICATIONS OF PHASOR MEASUREMENT UNITS}

This bubble chart illustrates the target synchrophasor applications for the electric power industry, mainly based on $[1,2]$. The applications analyzed in this report were selected from this chart.

1 = Planned \& developing, 2 = Engineering studies offline, 3 = Testing, 4=Fully implemented (NY ISO also installed 938 automated capacitors)

\begin{tabular}{|c|c|c|c|}
\hline Bubble Chart & Build Metrics and Project Description & Core Metrics & $\begin{array}{c}\text { Number of } \\
\text { Instances }\end{array}$ \\
\hline $\begin{array}{l}\text { Oscillation } \\
\text { detection }\end{array}$ & $\begin{array}{ll}\text { - } & \text { IPC-1 (oscillation energy and mode } \\
& \text { meter monitoring) } \\
\text { - } & \text { MISO-1 (oscillation monitoring) } \\
\text { - } & \text { PJM-1 } \\
\text { - } & \text { WECC }-4 \text { (oscillation energy and mode } \\
& \text { meter monitoring) } \\
\text { - } & \text { Entergy }-4\end{array}$ & $\begin{array}{ll}\text { - } & \text { IPC-1 } \\
\text { - } & \text { MISO-3/4 } \\
\text { - } & \text { ISO-NE (model } \\
& \text { analysis)-2 } \\
\text { - } & \text { ISO-NE phasor point-4 } \\
\text { - } & \text { WECC-3 } \\
\text { - } & \text { NYISO-4 } \\
\text { - } & \text { Duke-1 } \\
\text { - } & \text { PJM-3 }\end{array}$ & 9 \\
\hline $\begin{array}{l}\text { Phase angle } \\
\text { visualization/ } \\
\text { monitoring }\end{array}$ & $\begin{array}{ll}\text { Angle/frequency monitoring } \\
\text { - } & \text { ATC-3 }-3 \\
\text { - } & \text { CCET-4 } \\
\text { - } & \text { FP\&L-1 } \\
\text { - } & \text { IPC-1 } \\
\text { - } & \text { ISO-NE-1 } \\
\text { - } & \text { Midwest E--1 } \\
\text { - } & \text { PJM-4 } \\
\text { - } & \text { WECC-4 } \\
\text { - } & \text { Lafayette-4 } \\
\text { - } & \text { NY ISO-4 } \\
\text { - } & \text { Entergy-4 }\end{array}$ & $\begin{array}{ll}\text { - } & \text { WECC }-4 \\
\text { - } & \text { NYISO phase angle } \\
& \text { monitoring-4 } \\
\text { - } & \text { PJM-1 } \\
\text { - } & \text { FPL }-4\end{array}$ & 12 \\
\hline $\begin{array}{l}\text { Frequency } \\
\text { event detection }\end{array}$ & & $\begin{array}{ll}\text { - } & \text { ATC frequency } \\
& \text { monitoring-3 } \\
\text { - } & \text { MISO-3/4 } \\
\text { - } & \text { ISO-NE phasor point- } 4 \\
\text { - } & \text { WECC }-4 \\
\text { - } & \text { NYISO }-4\end{array}$ & 5 \\
\hline $\begin{array}{l}\text { Voltage } \\
\text { stability } \\
\text { monitoring }\end{array}$ & $\begin{array}{ll}\text { - } & \text { FP\&L-1 } \\
\text { - } & \text { IPC-1 } \\
\text { - } & \text { ISO-NE-1 } \\
\text { - } & \text { Midwest E.-1 } \\
\text { - } & \text { NY ISO-4 } \\
\text { - } & \text { WECC-4 }-4 \\
\text { - } & \text { CCET-4 } \\
\text { - } & \text { Entergy-4 }\end{array}$ & $\begin{array}{ll}\text { - } & \text { IPC-1 } \\
\text { - } & \text { ATC-3 } \\
\text { - } & \text { MISO-3/4 } \\
\text { - } & \text { ISO-NE ROSE-2 } \\
\text { - } & \text { NECC-4 } \\
\text { NYISO-4 }\end{array}$ & 11 \\
\hline $\begin{array}{l}\text { Alarming/event } \\
\text { management }\end{array}$ & - $\quad F P \& L-1$ (disturbance analysis) & $\begin{array}{ll}\text { - } & \text { ATC disturbance } \\
\text { monitoring-3 } \\
\text { - } \\
\text { NYISO event } \\
\text { detection/alarm-4 }\end{array}$ & 3 \\
\hline $\begin{array}{l}\text { - Islanding } \\
\text { detection }\end{array}$ & & $\begin{array}{l}\text { - } \quad \text { ATC }-3 \\
\text { - } \quad \text { WECC }-4\end{array}$ & 2 \\
\hline
\end{tabular}




\begin{tabular}{|c|c|c|c|}
\hline Bubble Chart & Build Metrics and Project Description & Core Metrics & $\begin{array}{c}\text { Number of } \\
\text { Instances }\end{array}$ \\
\hline & $\begin{array}{l}\text { - Power system restoration } \\
\circ \quad \text { WECC }-4\end{array}$ & - $\quad$ WECC -4 & 1 \\
\hline $\begin{array}{l}\text { Model } \\
\text { validation and } \\
\text { improvement } \\
\text { (general) }\end{array}$ & $\begin{array}{l}\text { - } \quad \text { IPC-1 } \\
\text { - } \quad \text { WECC }-1 \\
\text { Steady state model benchmarking } \\
\text { - } \quad \text { ATC }-1 \\
-\quad \text { CCET-1 } \\
-\quad \text { Midwest E.-1 } \\
-\quad \text { WECC }-4 \\
-\quad \text { ATC }-3\end{array}$ & $\begin{array}{l}\text { - } \text { IPC-Detect disturbances \& } \\
\text { analyze for model } \\
\text { validation-2 } \\
\text { - } \quad \text { ATC general "tools" } \\
\text { validation-1 } \\
\text { - } \quad \text { MISO-1 } \\
\text { - ISO-NE-2/4 } \\
\text { - } \quad \text { WECC }-4 \\
\text { - NYISO } 4\end{array}$ & 8 \\
\hline $\begin{array}{ll}\text { - } & \text { State } \\
\text { estimation } \\
\text { (specific } \\
\text { model) }\end{array}$ & $\begin{array}{ll}\text { Improved state estimation } \\
\text { - } & \text { ATC-3 } \\
\text { - } & \text { CCET-1 } \\
\text { - } & \text { FP\&L-1 } \\
\text { - } & \text { Midwest E.-1 } \\
\text { - } & \text { MISO-1 (state estimation integration) } \\
- & \text { NY ISO-4 } \\
\text { - } & \text { WECC }-4 \\
\text { - } & \text { Entergy }-4\end{array}$ & $\begin{array}{ll}\text { - } & \text { WECC-4 } \\
\text { - } & \text { NYISO-4 } \\
\text { - } & \text { Duke-3 } \\
\text { - } & \text { PJM-3 }\end{array}$ & 10 \\
\hline $\begin{array}{ll}\text { - } & \text { Power } \\
\text { plant } \\
\text { (specific } \\
\text { models) }\end{array}$ & & $\begin{array}{l}\text { - } \text { IPC wind plants (also some } \\
\text { other generators) -1 \& } 2 \\
\text { - } \quad \text { ISO-NE nuclear plant } \\
\text { model }-4 \\
\text { - } \quad \text { WECC nuclear plant_-4 } \\
\text { - } \quad \text { PJM-1 (awaiting GSU } \\
\text { PMU) }\end{array}$ & 4 \\
\hline $\begin{array}{l}\text { Post event } \\
\text { analysis }\end{array}$ & 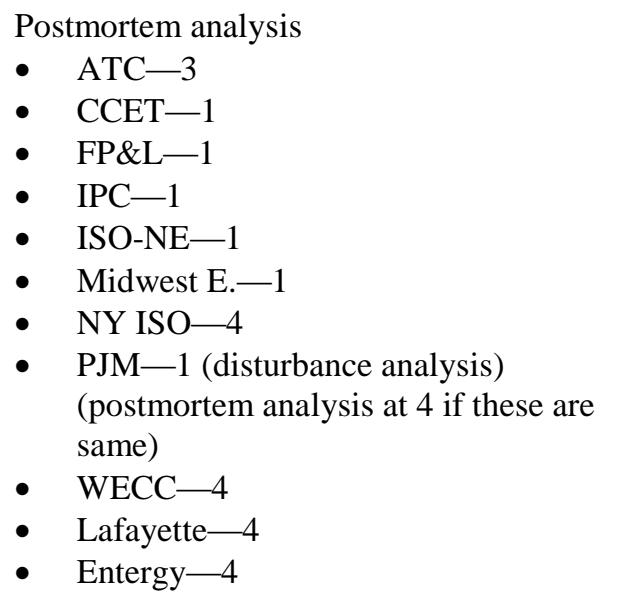 & $\begin{array}{ll}\text { - } & \text { ATC-2 } \\
\text { - } & \text { ISO-NE-2 } \\
\text { - } & \text { NYISO-4 } \\
\text { - } & \text { Duke-4 }\end{array}$ & 12 \\
\hline $\begin{array}{l}\text { Operator } \\
\text { training }\end{array}$ & & - $\quad$ WECC -4 & 1 \\
\hline $\begin{array}{l}\text { Wide area } \\
\text { awareness/ } \\
\text { visibility }\end{array}$ & $\begin{array}{l}\text { - Thermal overload monitoring } \\
\circ \quad \text { WECC - } 4 \\
\circ \quad \text { Maybe Lafayette }\end{array}$ & $\begin{array}{l}\text { - MISO enhanced real time } \\
\text { displays-2 }\end{array}$ & $\begin{array}{l}12 \\
\text { (13 with } \\
\text { Lafayette) }\end{array}$ \\
\hline
\end{tabular}




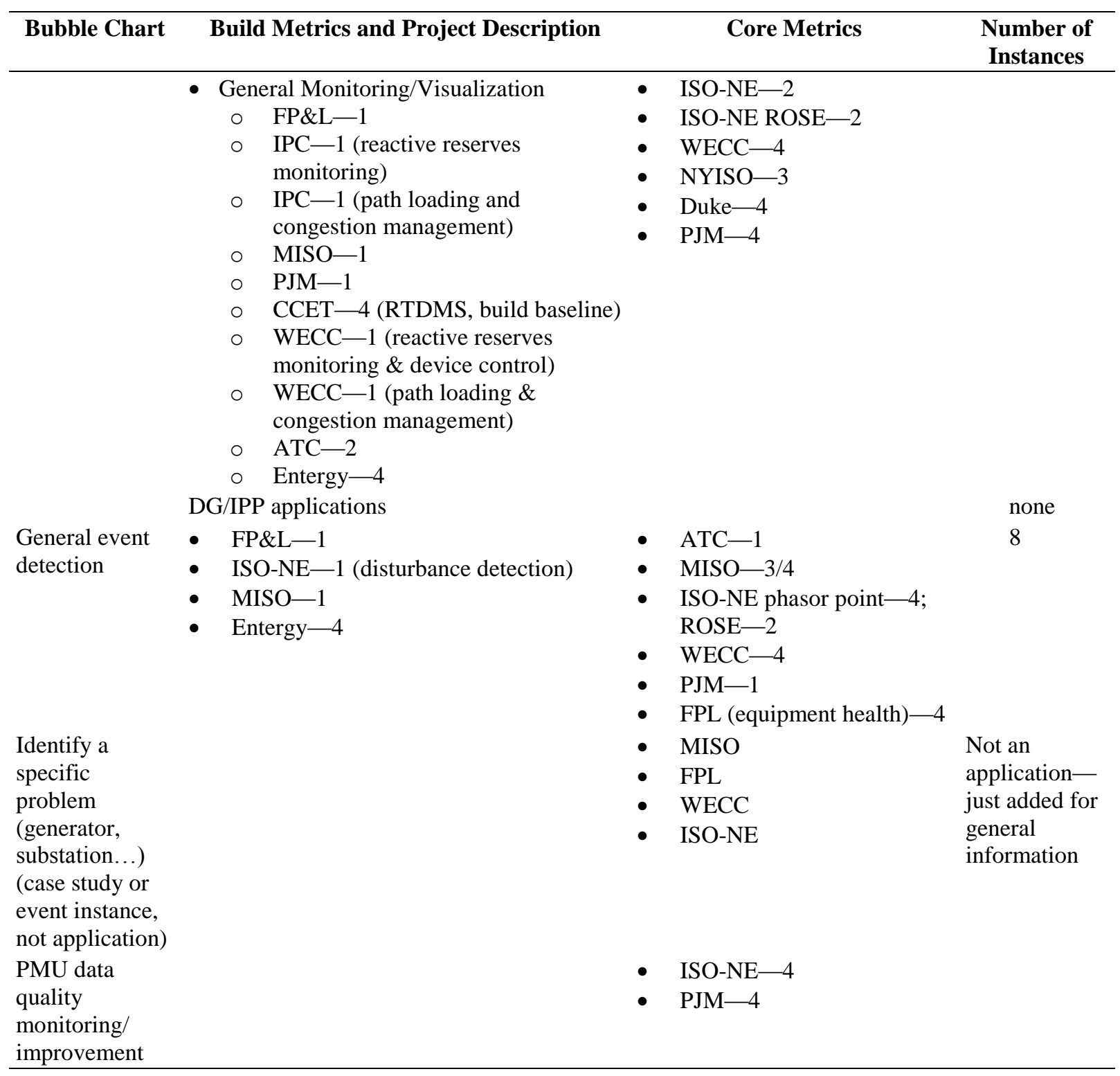

\section{Description:}

- Separate bullets for all instances of a recipient having this application

○ Solid bullet if the application is a category

- Circle bullet if the application is a subcategory

- First column is based on [1,2].

○ Rows that begin with "bullets" are subsets of special cases of the overall category

- Second column is the list of applications from the Build Metrics and project descriptions on the website (https://smartgrid.gov/sites/default/files/synchrophasor_project_status_110114-3.pdf), and instances (recipients) if reported there

- If the application is the same or similar to one in the first column, it is in the same line as the first column

- If the application is a subset of the first column, it is listed as a bullet

- Third column is instances (recipients) of column 1 application mentioned in core metrics

- Fourth column (number of instances) $=$ number if in \{column 2 OR column 3 \} 


\section{REFERENCES}

[1] (2014, Dec). Recovery Act Smart Grid Investments Synchrophasor Project Status. Available: https://www.smartgrid.gov/sites/default/files/synchrophasor_project status 110114-3.pdf.

[2] SMARTGRID.GOV, "Factors Affecting PMU Installation Costs," 2014. 
APPENDIX B. DYNAMIC LINE RATING MODEL 



\section{APPENDIX B. DYNAMIC LINE RATING MODEL}

This appendix provides a model for phasor-measurement-unit-based dynamic line rating technology $[1,2]$. This model is used in Section 5 of this report.

\section{B.1 NON-STEADY-STATE HEAT BALANCE}

$$
q_{\mathrm{c}}+q_{\mathrm{r}}+m \cdot C_{\mathrm{p}} \cdot \frac{d T_{\mathrm{avg}}}{d t}=q_{\mathrm{s}}+I^{2} \cdot R\left(T_{\mathrm{avg}}\right)
$$

where $q_{\mathrm{c}}$ is convective heat loss; $q_{\mathrm{r}}$ is radiated heat loss rate; $q_{\mathrm{s}}$ is rate of solar heat gain; $I$ is current of the transmission line; $m C_{p}$ is total heat capacity of conductor; $T_{\text {avg }}$ is the average conductor temperature; and $R\left(T_{\text {avg }}\right)$ is AC resistance of conductor at temperature, $T_{\text {avg }}$.

\section{B.2 CONVECTIVE HEAT LOSS $\left(\boldsymbol{q}_{\mathrm{c}}\right)$}

Convective heat loss is customarily divided into two types: natural convection $\left(q_{\mathrm{cn}}\right)$ and forced convection $\left(q_{\mathrm{c} 1}, q_{\mathrm{c} 2}\right)$.

\section{B.2.1 Natural Convection $\left(q_{\mathrm{cn}}\right)$}

$$
q_{\mathrm{cn}}=3.645 \cdot \rho_{f}^{0.5} \cdot D_{0}^{0.75} \cdot\left(T_{\mathrm{s}}-T_{\mathrm{a}}\right)^{1.25}
$$

where $D_{0}$ is the conductor diameter; $\rho_{\mathrm{f}}$ is air density; $T_{\mathrm{s}}$ is conductor surface temperature; $T_{\mathrm{a}}$ is ambient air temperature.

\section{B.2.2 Forced Convection}

$$
\begin{gathered}
q_{c 1}=K_{\text {angle }} \cdot\left[1.01+1.35 \cdot N_{\mathrm{Re}}^{0.52}\right] \cdot k_{\mathrm{f}} \cdot\left(T_{\mathrm{s}}-T_{\mathrm{a}}\right) \\
q_{c 2}=K_{\text {angle }} \cdot 0.754 \cdot N_{\mathrm{Re}}^{0.6} \cdot k_{\mathrm{f}} \cdot\left(T_{\mathrm{s}}-T_{\mathrm{a}}\right)
\end{gathered}
$$

Wind direction factor $K_{\text {angle }}$ is

$$
K_{\text {angle }}=1.1194-\cos (\phi)+0.194 \cdot \cos (2 \phi)+0.368 \sin (2 \phi),
$$

where $\phi$ is the angle between the wind direction and the conductor axis.

Reynolds number, $N_{\mathrm{Re}}$, is given as

$$
N_{\mathrm{Re}}=\frac{D_{0} \cdot \rho_{f} \cdot V_{\mathrm{w}}}{\mu_{f}},
$$

where $V_{\mathrm{w}}$ is the wind velocity; $\mu_{f}$ is the dynamic viscosity of air.

The dynamic viscosity of air is 


$$
\mu_{f}=\frac{1.458 \cdot 10^{-6} \cdot\left(T_{\text {film }}+273\right)^{1.5}}{T_{\text {film }}+383.4}
$$

The air density is

$$
\rho_{f}=\frac{1.293-1.525 \cdot 10^{-4} \cdot H_{e}+6.379 \cdot 10^{-9} \cdot H_{e}{ }^{2}}{1+0.00367 \cdot T_{\mathrm{film}}}\left[\mathrm{kg} / \mathrm{m}^{3}\right]
$$

Thermal conductivity of air is

$$
k_{f}=2.424 \cdot 10^{-2}+7.477 \cdot 10^{-5} \cdot T_{\text {film }}-4.407 \cdot 10^{-9} \cdot T_{\text {film }}^{2} .
$$

Average temperature of the boundary layer is

$$
T_{\text {film }}=\frac{T_{\mathrm{s}}+T_{\mathrm{a}}}{2} .
$$

\section{B.3 RADIATED HEAT LOSS RATE $\left(q_{\mathrm{r}}\right)$}

$$
q_{\mathrm{r}}=17.8 \cdot D_{0} \cdot \varepsilon \cdot\left[\left(\frac{T_{\mathrm{s}}+273}{100}\right)^{4}-\left(\frac{T_{\mathrm{a}}+273}{100}\right)^{4}\right],
$$

where $\varepsilon$ is emissivity.

\section{B.4 RATE OF SOLAR HEAT GAIN $\left(q_{s}\right)$}

$$
q_{\mathrm{s}}=\alpha \cdot Q_{s e} \cdot \sin (\theta) \cdot \mathrm{A}^{\prime},
$$

where $\alpha$ is solar absorptivity; $\mathrm{A}^{\prime}$ is the projected area of the conductor.

The effective angle of incidence of the sun's rays is

$$
\theta=\arccos \left[\cos \left(H_{\mathrm{c}}\right) \cdot \cos \left(Z_{\mathrm{c}}-Z_{\mathrm{l}}\right)\right]
$$

The solar altitude of the sun, $H_{c}$, is

$$
H_{c}=\arcsin [\cos (L a t) \cdot \cos (\delta) \cdot \cos (\omega)+\sin (\text { Lat }) \sin (\delta)] .
$$

The solar declination, $\delta$, is

$$
\delta=23.46 \cdot \sin \left[\frac{284+N}{365} \cdot 360\right]
$$

The solar azimuth, $Z_{c}$, is 


$$
Z_{c}=C+\arctan (\chi)
$$

where

$$
\chi=\frac{\sin (\omega)}{\sin (\text { Lat }) \cdot \cos (\omega)-\cos (\text { Lat }) \cdot \tan (\delta)},
$$

and $C$ is the solar azimuth constant (in degrees) and is a function of the "Hour angle" $\omega$ and the solar azimuth variable $\chi$ as shown in the Table B.1:

Table B.1. Solar azimuth constant $C$

\begin{tabular}{ccc}
\hline Hour angle $\boldsymbol{\omega}$, degrees & $\boldsymbol{C}$ if $\boldsymbol{\chi}>=\mathbf{0}$ degrees & $\boldsymbol{C}$ if $\boldsymbol{\chi}<\mathbf{0}$ degrees \\
\hline$-180 \leq \omega<0$ & 0 & 180 \\
$0 \leq \omega<180$ & 180 & 360 \\
\hline
\end{tabular}

The solar heat intensity at the earth's surface, $Q_{\text {se }}$, is

$$
Q_{\text {se }}=K_{\text {solar }} Q_{s},
$$

where

$$
K_{\text {solar }}=1+1.148 \cdot 10^{-4} \cdot H_{e}-1.108 \cdot 10^{-8} \cdot H_{e}^{2} .
$$

The total heat flux density is

$$
Q_{\mathrm{s}}=A+B H_{c}+C_{c}{ }^{2}+D H_{c}{ }^{3}+E H_{c}{ }^{4}+F H_{c}{ }^{5}+G H_{c}{ }^{6} .
$$

Table B.2. Polynomial coefficients for solar heat intensity as a function of solar altitude

\begin{tabular}{cccccccc}
\hline & $\mathbf{A}$ & $\mathbf{B}$ & $\mathbf{C}$ & $\mathbf{D}$ & $\mathbf{E}$ & $\mathbf{F}$ & $\mathbf{G}$ \\
\hline $\begin{array}{c}\text { Clear } \\
\text { atmosphere }\end{array}$ & -42.2391 & 63.8044 & -1.9220 & $3.46921 \times 10^{-2}$ & $-3.61118 \times 10^{-4}$ & $1.94318 \times 10^{-6}$ & $-4.07608 \times 10^{-9}$ \\
$\begin{array}{c}\text { Industrial } \\
\text { atmosphere }\end{array}$ & 53.1821 & 14.2110 & $6.6138 \times 10^{-1}$ & $-3.1658 \times 10^{-2}$ & $5.4654 \times 10^{-4}$ & $-4.3446 \times 10^{-6}$ & $1.3236 \times 10^{-8}$ \\
\hline
\end{tabular}

The solar heat gain is the amount of the solar heat energy delivered to the conductor, which depends on the sun's position in the sky. The original expression of $q_{\mathrm{s}}$ is plotted as Fig. B.4.1(A). 

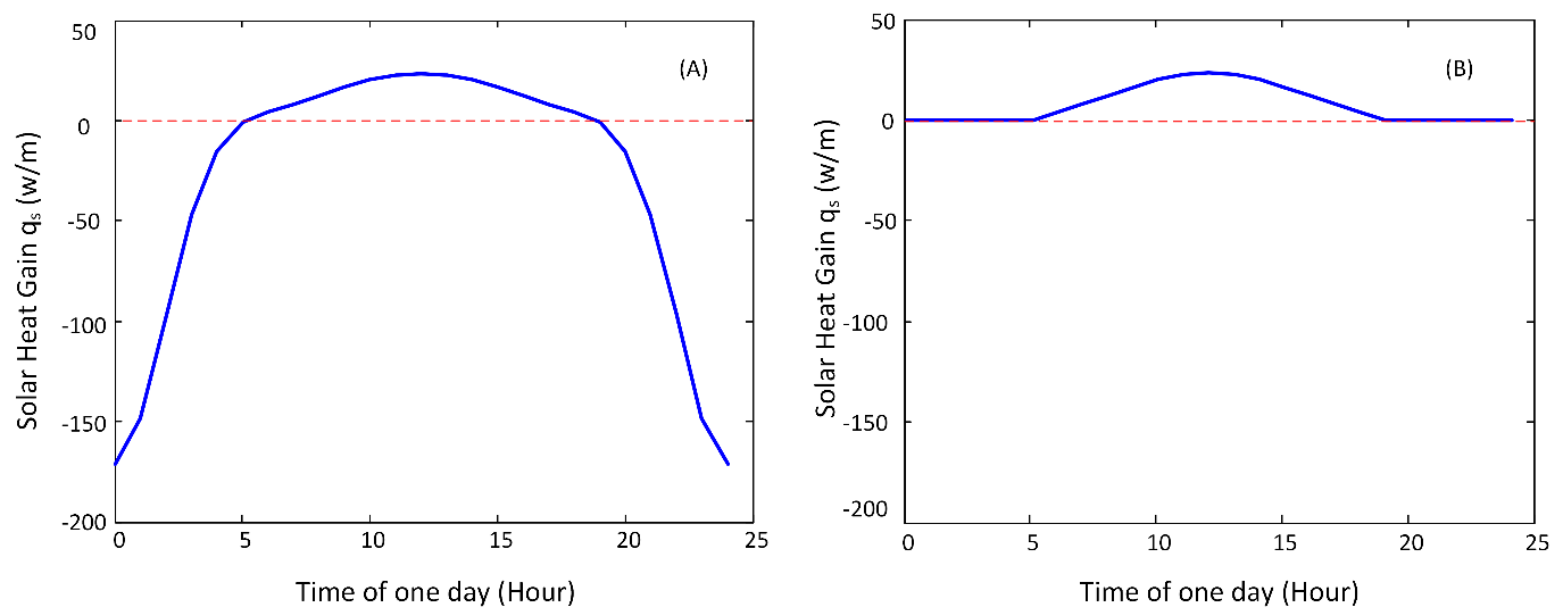

Fig. B.4.1 Solar heat gain in one day before and after modification.

The real data of solar irradiation, based on National Renewable Energy Laboratory measurements, are shown in Fig. B.4.2 [3]. We can see that before sunrise and after sunset, the minimum solar radiation is zero, meaning the minimum solar heat energy is zero. According to the definition and the measurements of the solar heat radiation, the expression of $q_{\mathrm{s}}$ can be modified as in Fig. B.4.1(B).

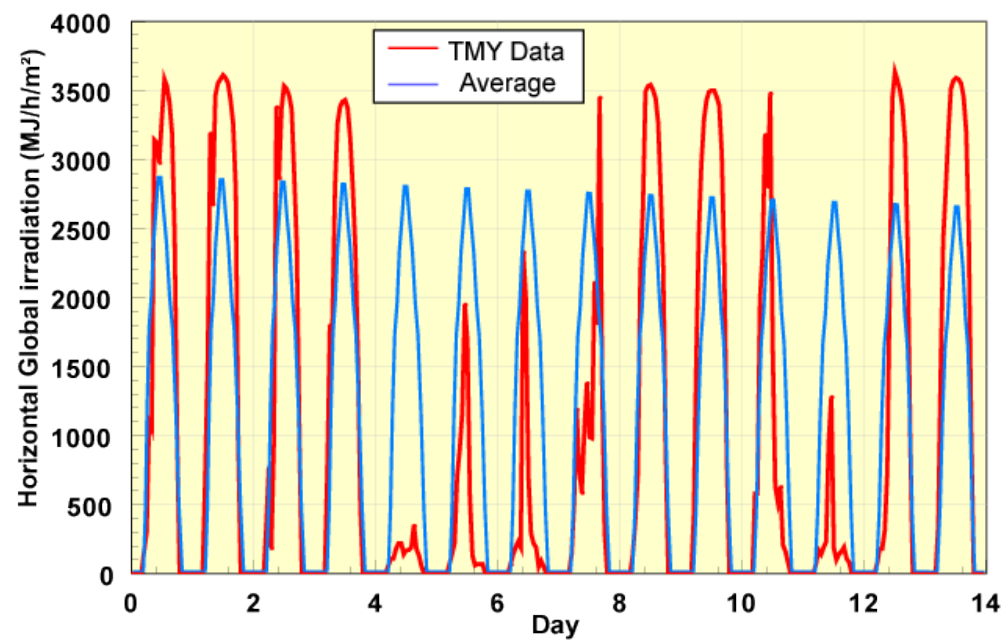

Fig. B.4.2. The typical meteorological year and average solar radiation data [3].

\section{B.5 CONDUCTOR ELECTRICAL RESISTANCE}

$$
R\left(T_{\text {avg }}\right)=\left[\frac{R\left(T_{\text {high }}\right)-R\left(T_{\text {low }}\right)}{T_{\text {high }}-T_{\text {low }}}\right] \cdot\left(T_{\text {avg }}-T_{\text {low }}\right)+R\left(T_{\text {low }}\right)
$$

\section{B.6 IMPEDANCE AND SHUNT ADMITTANCE ESTIMATED BY PMU MEASUREMENTS}

For the nominal $\pi$ model, the relationship between the line parameters and the sending and receiving end voltages and currents is as follows. 


$$
\left[\begin{array}{c}
V_{s} \\
I_{s}
\end{array}\right]=\left[\begin{array}{cc}
1+\frac{Y Z}{2} & Z \\
Y\left(1+\frac{Y Z}{4}\right) & 1+\frac{Y Z}{2}
\end{array}\right]\left[\begin{array}{c}
V_{R} \\
I_{R}
\end{array}\right]
$$

The impedance and admittance can be solved by the following equations.

$$
\begin{gathered}
Y=\frac{2\left(I_{\mathrm{S}}-I_{\mathrm{R}}\right)}{V_{\mathrm{S}}+V_{\mathrm{R}}} \\
Z=\frac{V_{\mathrm{S}}^{2}-V_{\mathrm{R}}^{2}}{V_{\mathrm{S}} I_{\mathrm{R}}+V_{\mathrm{R}} I_{\mathrm{S}}}
\end{gathered}
$$

\section{B.7 STEPS}

Step 1: The voltage and current phasors of both ends from PMU measurement are imported to the model.

Step 2: The impedance and admittance of the transmission line are computed by Eqs. (23) and (24).

Step 3: The average temperature of the conductor is computed by Eq. (21).

Step 4: A series of calculations must be performed, each applying to a short period of time (as was done for the transient case), during which the current and weather parameters (wind speed and direction, ambient temperature, etc.) are assumed to remain constant and equal to their values at the beginning of the interval. Weather condition data are imported to the model.

Step 5: The maximum current of the conductor for the time interval $(\Delta \mathrm{t})$ is calculated using the nonsteady-state heat balance equation, Eq. (1).

Step 6: At the next time step, the model refreshes the average temperature of conductor and weather conditions. Repeat Step 5. 


\section{REFERENCES}

[1] IEEE, "IEEE Standard for Calculating the Current-Temperature Relationship of Bare Overhead Conductors", IEEE Std 738-1993.

[2] Sveinn Rúnar Júlíusson, "Using PMU Measurements to Assess Dynamic Line Rating of Transmission Lines", Aalborg University, 2013.

[3] Analysis of Solar Irradiance Data Sets. Available: http://pveducation.org/pvcdrom/properties-ofsunlight/analysis-of-solar-irradiance-data-sets. 
APPENDIX C. INPUT DATA FOR DYNAMIC LINE RATING MODEL 



\section{APPENDIX C. INPUT DATA FOR DYNAMIC LINE RATING MODEL}

This appendix presents the data used for the dynamic line rating model. The data are used to calculate the results in Section 5.2.2 of this report. The model is described in Appendix B.

\section{C.1 BASE CASE}

Table C.1 Parameters of the base case

\begin{tabular}{lc}
$\begin{array}{l}\text { Voltage level } \\
\text { Total length }\end{array}$ & $220 \mathrm{kV}$ \\
Conductor & $59 \mathrm{~km}$ \\
\hline & Phasor measurement unit measurement \\
\hline Sending end voltage $\boldsymbol{V}_{\boldsymbol{s}}$ & $220.0<0.01^{\circ} \mathrm{kV}$ \\
Sending end current $\boldsymbol{I}_{\boldsymbol{s}}$ & $797.8<-5.66^{\circ} \mathrm{A}$ \\
Receiving end voltage $\boldsymbol{V}_{\boldsymbol{r}}$ & $214.8<-5.48^{\circ} \mathrm{kV}$ \\
Receiving end current $\boldsymbol{I}_{\boldsymbol{r}}$ & $800.1 \angle-8.03^{\circ} \mathrm{A}$ \\
\hline & \\
\hline Wind speed & $0.61 \mathrm{~m} / \mathrm{s}$ \\
Ambient temperature & $40^{\circ} \mathrm{C}$ \\
\hline ACSR = aluminum conductor, steel-reinforced & Weather
\end{tabular}

\section{C.2 CONDITION}

Table C.2 Parameters of the calculation condition

\begin{tabular}{lll}
\hline & Value & SI Unit \\
\hline Emissivity & 0.8 & \\
Solar absorptivity & 0.8 & \\
Maximum allowable conductor temperature & 100 & ${ }^{\circ} \mathrm{C}$ \\
Conductor outside diameter $(\boldsymbol{D} 0)$ & 28.14 & $\mathrm{~mm}$ \\
Conductor AC resistance $\boldsymbol{R}\left(\mathbf{2 5}^{\circ} \mathbf{C}\right)$ & $7.283 \times 10^{-5}$ & $\Omega / \mathrm{m}$ \\
Conductor AC resistance $\boldsymbol{R}^{\left(\mathbf{7 5}^{\circ} \mathbf{C}\right)}$ & $8.688 \times 10^{-5}$ & $\Omega / \mathrm{m}$ \\
Latitude & $30^{\circ}$ North & \\
Atmosphere & Clear & $\mathrm{m}$ \\
Line elevation $\left(\boldsymbol{H}_{\boldsymbol{e}}\right)$ & 0 & \\
Solar altitude in summer $\left(\boldsymbol{H}_{\mathbf{c}}\right)$ & $\mathrm{June} 10($ Day 161$)$ & $\mathrm{kg} / \mathrm{m}$ \\
The weights of the steel $(\mathbf{m})$ & 1.116 & $\mathrm{~J} /\left(\mathrm{kg}{ }^{\circ} \mathrm{C}\right)$ \\
Heat $\left(\boldsymbol{C}_{\mathbf{p}}\right)$ & 955 & $\mathrm{~min}$ \\
Time interval & 10 & \\
\hline
\end{tabular}

\section{C.3 WIND SPEED AND AMBIENT TEMPERATURE IN ONE DAY (SUMMER AND WINTER)}

Temperature_Summer $=[35,34.2,33,32.5,31,30.5,30,29.6,29,30.8,32,34,35,35.5,36,37,38,40$, $38,36,33,32.5,31,28]$ 
Windspeed_Summer $=[2.1,2.16,2.3,3.6,4.5,4,2,3.5,4.6,4.1,3.5,2.1,3,3.4,4.4,4.2,3,1.2,2.5,1.4$, $2,1.5,2,3.3]$

Temperature_Winter $=[5,4.2,3,2.5,1,0.5,0,-0.4,-1,0.8,2,4,5,5.5,6,7,8,10,8,6,3,2.5,1,-2]$

Windspeed_Winter $=[0.5,0.75,0.63,0.4,1.2,0.8,0.67,1.32,1.35,1.5,1.0,0.79,0.92,0.34,0.4,0.62$, $0.70,1.2,2,1.5,1.8,2.6,1.5,2]$ 